\title{
Management of Statin Intolerance in 2018: Still More Questions Than Answers
}

\author{
Peter P. Toth ${ }^{1,2}$ - Angelo Maria Patti ${ }^{3}$. Rosaria Vincenza Giglio ${ }^{3} \cdot$ \\ Dragana Nikolic $^{3}$ - Giuseppa Castellino ${ }^{3}$ - Manfredi Rizzo ${ }^{3} \cdot$ Maciej Banach $^{4,5,6} \mathbb{C}_{(}$
}

Published online: 9 January 2018

(C) The Author(s) 2018. This article is an open access publication

\begin{abstract}
Statin therapy is generally well tolerated and very effective in the prevention and treatment of cardiovascular disease, regardless of cholesterol levels; however, it can be associated with various adverse events (myalgia, myopathy, rhabdomyolysis, and diabetes mellitus, among others). Patients frequently discontinue statin therapy without medical advice because of perceived side effects and consequently increase their risk for cardiovascular events. In patients with statin intolerance, it may be advisable to change the dose, switch to a different statin, or try an alternate-day regimen. If intolerance is associated with all statins-even at the lowest dose-non-statin drugs and certain nutraceuticals can be considered. This review focuses on the definition of statin intolerance and on the development of clinical and therapeutic strategies for its management, including emerging alternative therapies.
\end{abstract}

Peter P. Toth and Angelo Maria Patti contributed equally to this paper.

Maciej Banach

maciejbanach77@gmail.com

1 CGH Medical Center, Sterling, IL, USA

2 Ciccarone Center for the Prevention of Cardiovascular Disease, Johns Hopkins University School of Medicine, Baltimore, MD, USA

3 Biomedical Department of Internal Medicine and Medical Specialties, University of Palermo, Palermo, Italy

4 Chair of Nephrology and Hypertension, Department of Hypertension, WAM University Hospital in Lodz, Medical University of Lodz, Zeromskiego 113, 90-549 Lodz, Poland

5 Polish Mother's Memorial Hospital Research Institute, Lodz, Poland

6 Cardiovascular Research Centre, University of Zielona Gora, Zielona Gora, Poland

\section{Key Points}

Statins are the gold standard for managing dyslipidemia in patients with elevated cardiovascular risk. Discontinuation of statin therapy is associated with an increase in cardiovascular events.

An important issue in the management of patients with statin intolerance/statin-associated muscle symptoms is the need to avoid statin discontinuation. Options include step-by-step reduction of the statin dose (dechallenge), switching to a different statin, or using intermittent dosages (alternate-day therapy).

New non-statin agents, as well as alternative therapy with nutraceuticals with or without a non-statin drug, may help to improve therapy adherence and reduce the risk for patients with true statin intolerance. Further studies in patients intolerant to statins are necessary to confirm the effectiveness and safety of nutraceuticals. In addition, these agents will have to be tested in long-term randomized controlled trials to more definitively assess their efficacy for reducing cardiovascular risk.

\section{Introduction}

Statins (3-hydroxy-3-methylglutaryl coenzyme A [HMG$\mathrm{CoA}$ ] reductase inhibitors) effectively reduce the burden of atherogenic lipoprotein in serum [1]. Statins are a mainstay globally in cardiovascular (CV) pharmacotherapy [2], not 
only in patients with dyslipidemia [3] but also in patients with coronary artery disease (CAD), acute coronary syndromes (ACS), diabetes mellitus (DM), stroke, hypertension, and chronic kidney disease (CKD) (with or without coexistent dyslipidemia) [4]. The decrease in CV mortality incidence worldwide has been attributed to the lowering of cholesterol to prevent $\mathrm{CAD}$ and total $\mathrm{CV}$ disease (CVD) [5]. A $21 \%$ decrease in CVD mortality and morbidity (stroke and fatal coronary events) can be achieved by lowering low-density lipoprotein cholesterol (LDL-C) by $1.0 \mathrm{mmol} / \mathrm{l}(38.7 \mathrm{mg} / \mathrm{dl})$ [6]. The beneficial role of statins in primary and secondary prevention [7-9] is among the most intensively studied issues in modern medicine. The Cholesterol Treatment Trialists (CTT) collaboration demonstrated a $12 \%$ reduction in all-cause mortality per $\mathrm{mmol} / \mathrm{l}$ reduction in LDL-C and corresponding significant reductions in myocardial infarction (MI) or coronary death (23\%), the need for coronary revascularization (24\%), and in fatal or non-fatal stroke $(17 \%)$ after 5 years of statin therapy [10].

Statins are generally safe and well tolerated, but not all patients are able to use a statin. Statin intolerance is most frequently attributed to muscle-related adverse events [11-14]. Statin discontinuation rates remain high, even among patients with coronary heart disease (CHD) (over $50 \%$ after 1 year) $[15,16]$. Unfortunately, statin non-adherence correlates highly with risk for acute CV events, increasing the risk for recurrent MI and CHD [17, 18]. This narrative review discusses the definition, diagnosis, and management of statin intolerance as well as novel treatment approaches that might be considered.

\section{Methods}

\subsection{Search Strategy}

We searched electronic databases (MEDLINE [1990-30 April 2017], Embase, and SCOPUS [1993-30 April 2017], DARE [1993-30 April 2017]) and Web of Science Core Collection (up to 30 April 2017), and abstracts from national and international meetings. Where necessary, the relevant authors were contacted to obtain further data. The main search terms were $<$ statins intolerance $>$ OR $<$ statinassociated side effects $>$ OR $<$ statin-related side effects $>$ OR $<$ statin-induced side effects $>$ OR $<$ statin-associated/ related symptoms $>$ OR $<$ statin associated muscle symptoms $>$ OR SAMS OR $<$ statin-associated/related myalgia $>$ OR < statin associated/related myopathy $>$ AND $<$ newonset diabetes $>$ OR NOD AND $<$ management $>$ OR $<$ alternative therapy $>$ OR $<$ alternate-day therapy $>$ OR $<$ nutraceuticals $>$ OR $<$ non-statin drugs $>$ AND $<$ cardiovascular disease $>$ OR CVD OR $<\mathrm{CV}$ event $>$ OR
$<\mathrm{CV}$ risk $>$. We used the wild-card term "**" to increase the sensitivity of the search strategy.

The main inclusion criterion was data from studies, trials, and meta-analyses on the association between statin intolerance and CVD and on statin intolerance and use of alternative therapies. Two authors (AMP and RVG) examined every article separately, also investigating reviews, case studies, and experimental studies. Any doubt or issues were resolved by discussion with a third party (MB).

\subsection{Epidemiology and Definition of Statin Intolerance}

Although statins are the mainstay of lipid-lowering treatment, as many as $20 \%$ of individuals with a clinical indication for statin therapy are unable to take a daily statin because of some degree of intolerance [19], and 40-75\% of patients discontinue their statin therapy within 1-2 years after initiation [18].

The definition of statin intolerance (Table 1) is a question of great interest and debate [20]. Intolerance (partial or complete) should be defined as an inability to tolerate a suitable dose of a statin required for a given patient's CV risk (e.g., intolerance of atorvastatin $40-80 \mathrm{mg}$ or rosuvastatin $20-40 \mathrm{mg}$ by a patient with ACS). Intolerance can become clinically apparent with a variety of clinical adverse effects that significantly impair organ function and/ or quality of life after intake of any statin at any dose (complete intolerance) with or without associated laboratory abnormality (increase in creatine kinase [CK]), or can manifest with temporal associations between symptoms and the onset of therapy or increased dose (partial intolerance) (usually within 3-6 months). Discontinuation or dose reduction of the drug (statin dechallenge) or replacement with another statin can result in remission of symptoms and confirms a diagnosis of statin intolerance [20]. According to Mancini et al. [21], about 70-80\% of statin-treated patients are tolerant to treatment, and 20-30\% are suspected to be statin intolerant. These authors also note that a certain diagnosis of statin intolerance is found in about 5-6\% of patients [21]. According to an evaluation by Banach and colleagues [14, 18], a step-bystep approach (very careful physical examination of the patient, assessing patient history and risk for drug interactions, and exclusion of all possible risk factors and conditions that might increase the risk of statin intolerance, including the so-called "nocebo effect"-psychologically conditioned symptoms as a result of expectations due to achieved knowledge of drug-related side effects) yields a diagnosis of complete statin intolerance in only $2-3 \%$ of patients. 
Table 1 Definitions of statin intolerance

\begin{tabular}{|c|c|c|c|}
\hline Society & Definition of statin intolerance & Year & References \\
\hline $\begin{array}{l}\text { National Lipid Association } \\
\text { (NLA) }\end{array}$ & $\begin{array}{l}\text { "Inability to tolerate at least two statins: one statin at the lowest starting daily dose and another } \\
\text { statin at any daily dose, due to either objectionable symptoms (real or perceived) or } \\
\text { abnormal laboratory determinations, which are temporally related to statin treatment and } \\
\text { reversible upon statin discontinuation" }\end{array}$ & 2014 & {$[22]$} \\
\hline $\begin{array}{l}\text { International Lipid Expert } \\
\text { Panel (ILEP) }\end{array}$ & $\begin{array}{l}\text { "Inability to tolerate at least two statins: one statin at the lowest starting daily dose and another } \\
\text { statin at any daily dose, due to either objectionable symptoms (real or perceived) or } \\
\text { abnormal laboratory determinations, which are temporally related to statin treatment and } \\
\text { reversible upon statin discontinuation. The resolution of symptoms or changes in biomarkers } \\
\text { or even significant improvement with dose reduction or withdrawal of treatment; symptoms } \\
\text { or changes in biomarkers are not attributable to predispositions (drug-drug interactions and } \\
\text { recognized conditions), increasing the risk of statin intolerance" }\end{array}$ & 2014 & {$[23]$} \\
\hline $\begin{array}{l}\text { European Atherosclerosis } \\
\text { Society (EAS) }\end{array}$ & $\begin{array}{l}\text { "The assessment of statin-associated muscle symptoms (SAMS) includes the nature of muscle } \\
\text { symptoms, increased creatine kinase levels and their temporal association with initiation of } \\
\text { therapy with statin, and statin therapy suspension and rechallenge" }\end{array}$ & 2015 & {$[24]$} \\
\hline $\begin{array}{l}\text { Canadian Consensus } \\
\text { Working Group }\end{array}$ & $\begin{array}{l}\text { "A clinical syndrome, not caused by drug interactions or risk factors for untreated intolerance } \\
\text { and characterized by significant symptoms and/or biomarker abnormalities that prevent the } \\
\text { long-term use and adherence to statins documented by challenge/dechallenge/rechallenge, } \\
\text { where appropriate, using at least two statins, including atorvastatin and rosuvastatin, and that } \\
\text { leads to failure of maintenance of therapeutic goals, as defined by national guidelines" }\end{array}$ & 2016 & {$[25]$} \\
\hline
\end{tabular}

The definition of statin intolerance has evolved over the years. In late 2014, the National Lipid Association (NLA) defined this syndrome as an inability to tolerate at least two statins-one statin at the lowest starting daily dose and another statin at any daily dose-due to either objectionable symptoms (real or perceived) or abnormal laboratory determinations that are temporally related to statin treatment and reversible upon statin discontinuation [22]. In addition to this, the International Lipid Expert Panel (ILEP) definition included the resolution of symptoms or changes in biomarkers or even significant improvement with dose reduction or withdrawal of treatment; symptoms or changes in biomarkers are not attributable to predispositions (drug-drug interactions and recognized conditions), increasing the risk of statin intolerance [23]. The European Atherosclerosis Society (EAS) consensus paper suggested a more clinically oriented definition and recommended that the assessment of statin-associated muscle symptoms (SAMS) include the nature of muscle symptoms, increased CK levels and their temporal association with initiation of statin therapy, and statin therapy suspension and rechallenge [24]. In 2016, the Canadian Consensus Working Group update defined statin intolerance as "a clinical syndrome, not caused by drug interactions or risk factors for untreated intolerance and characterized by significant symptoms and/or biomarker abnormalities that prevent the long-term use and adherence to statins documented by challenge/dechallenge/rechallenge, where appropriate, using at least two statins, including atorvastatin and rosuvastatin, and that leads to failure of maintenance of therapeutic goals, as defined by national guidelines" [25]. This is the most complete and a very pragmatic definition of complete statin intolerance. The explicit inclusion of references to national guidelines and objectives in a definition of statin intolerance has the intent to ensure that the practical effort is justified for patients, colleagues, regulatory authorities, and taxpayers [25, 26].

\subsection{Symptoms and Biomarkers of Statin Intolerance}

\subsubsection{Symptoms of Statin Intolerance}

The patient's subjective assessment of the perceived risks and disadvantages compared with the benefits of therapy is important for an effective approach to statin intolerance. Most cases of statin intolerance are related to patient complaints; suspension of therapy due to laboratory abnormalities is much less common. Statin intolerance is not simply the occurrence of symptoms in general, but rather the symptoms that are perceived as unacceptable [27]. Identifying true cases of statin intolerance is, therefore, of great practical importance in order to avoid unnecessary suspension of statin therapy by patients who would otherwise benefit from them [27]. However, assessing the probability that negative symptoms are causally related to statins is often difficult. Symptoms (more than $75 \%$ ) are more likely to be attributable to statins if they appear within the first 3 months of statin therapy and if they improve after suspension and reoccur after reintroduction [28, 36]. Statins have specific adverse effects 
(myalgias 3-5\%; myopathy $0.1-0.2 \%$; new-onset diabetes [NOD] 9-27\%, and hepatotoxicity, usually <1\%) [27] demonstrable or not from abnormal blood markers, including muscle (e.g., CK) or liver function studies (hepatic transaminases-mainly alanine aminotransferase [ALT]) [27]. For the latter, it is worth emphasizing that in fact there is no confirmed link between statin therapy and liver damage, and most of the current guidelines and consensus papers recommend measuring transaminases only before statin therapy initiation and during treatment if symptoms develop [14].

The main adverse reactions due to statins include myalgia, myotoxicity, and NOD [28, 29]. The risk of developing NOD depends on the presence of prediabetes (insulin resistance, carbohydrate metabolism disorders), the number of metabolic syndrome components (overweight, elevated blood pressure, high triglycerides, low high-density lipoprotein cholesterol [HDL-C], and hyperglycemia), and the duration and intensity of statin therapy. As the number of metabolic syndrome components increases, so does the risk for NOD in statin-treated patients [30]. In general, one must treat approximately 1000 patients annually to see one new case of NOD on low-dose statin therapy, or 500 patients per year to see one new case on moderate- to high-dose statin therapy [31]. However, taking into account the available data, it is clear that the benefits associated with statin therapy outweigh the risk of NOD (for patients at high and very high CV risk, the number needed to treat $[\mathrm{NNT}]$ vs. the number needed to harm $[\mathrm{NNH}]$ is $>3-5$ times higher) [32-35].

In the JUPITER primary prevention trial, the $\mathrm{CV}$ and mortality benefits of statin therapy exceeded the diabetes hazard, including among those at higher risk for developing diabetes. During a follow-up period of up to 5 years, a total of 86 vascular events or deaths were avoided, with no NOD diagnosed in patients with no major diabetes risk factors (CV events $-39 \%, p=0.0001$; no increase of diabetes, $p=0.99$ ), and 93 vascular events or deaths were avoided for every 54 NOD cases diagnosed in patients with one or more factors for diabetes development (CV events $-39 \%$, $p=0.0001$; increase in diabetes $28 \%, p=0.01$ ). Moreover, statin therapy was associated with a time to NOD of only 5.4 weeks compared with placebo [36]. To reduce the risk of NOD while receiving statin therapy, patients should be advised to exercise, reduce caloric intake, lose weight, and stop smoking, all interventions that should be undertaken in any case.

Statin therapy should be continued in patients with NOD. In such cases, patient management includes a hypoglycemic diet, loss of excessive body weight, and prescription of antidiabetic drugs, if appropriate [34]. The approach to lipid lowering in overweight or obese primary prevention patients is to introduce statins after careful estimation of $\mathrm{CV}$ risk and treatment of adverse event risks when nonpharmacological therapy is not effective [35].

SAMS, including myalgia—ranging from mild to severe in intensity-muscle stiffness and tenderness, cramps, and loss of muscle strength [23, 37], are by far the most common adverse effects and one of the most important reasons for discontinuing statin therapy. The prevalence of SAMS is around $3-5 \%$ in randomized controlled trials including patients with dyslipidemia [38] and up to $20 \%$ in observational studies [39, 40], although the EAS consensus paper reported a SAMS prevalence as high as 29\% [24]. PRIMO (Prediction of Muscular Risk in Observational conditions), a survey conducted in general medicine clinics in France, showed that $10.5 \%$ of patients receiving statins reported muscle symptoms, though the prevalence varied with individual statins (fluvastatin had the lowest rate of SAMS, whereas simvastatin had the highest) [41]. The USAGE (Understanding Statin Use in America and Gaps in Education) study investigated current and former statin users via an internet-based survey and showed that SAMS occurred in $60 \%$ of current and $25 \%$ of former users and that SAMS were the primary reason for treatment discontinuation [42]. Finally, data from the STOMP (Effect of Statins on Skeletal Muscle Function and Performance) study, a randomized, double-blind, placebo-controlled trial, indicated that myalgia occurred in $9.4 \%$ of patients receiving atorvastatin but also in $4.6 \%$ of subjects receiving placebo, for an overall incidence of statin-attributable SAMS of $\sim 5 \%$ [43].

The NLA Task Force on Statin Safety (updated in 2014) [44] classified the clinical presentation of SAMS as four distinct entities: (1) myalgia, (2) myopathy, (3) myositis, and (4) myonecrosis (including rhabdomyolysis). Myalgia is defined as muscle pain or flu-like symptoms (heaviness, tenderness, stiffness, aches or cramps) with normal CK levels [44]. It is very important to know which muscle aches are typically associated with SAMS. Based on the proposal by the NLA, the SAMS Clinical Index (SAMSCI) score, recently updated by Rosenson et al. [45], provides the greatest score ( 3 points) for the typical large muscle symmetric (e.g., bilateral) aches, 2 points for bilateral aches of the smaller distal or proximal musculature, and 1 point for asymmetric, non-uniform symptoms [44]. In the STOMP study [43], subjects who reported myalgia while taking statins reported predominantly leg symptoms (hip flexor, quadriceps, hamstring, and/or calf aches; quadriceps or calf cramps; and/or quadriceps, hamstring, and/or calf fatigue), whereas those receiving placebo reported more diverse symptoms such as wholebody fatigue and groin pain $[43,44]$. The SAMS-CI score might be a very useful tool with which to confirm statinrelated myalgia and to exclude the nocebo effect. 
Myopathy with muscle weakness (not attributed to pain) can occur with normal or elevated CK [29]. Factors predisposing to the development of myopathy include age $>75$ years, female sex, renal and hepatic dysfunction, hypothyroidism, alcohol abuse, excessive physical exertion, genetic susceptibility, perioperative period, and concurrent use of drugs inhibiting the metabolism of statins, such as clarithromycin, erythromycin, azole antifungals, diltiazem, verapamil, amiodarone, fibrates (particularly gemfibrozil), cyclosporin, clopidogrel, sulfonamides, and red yeast rice $[23,34,37]$. It has been also observed that low levels of vitamin D and coenzyme Q10 (CoQ10) might increase the risk of statin intolerance; however, available data do not yet enable recommendations on their supplementation to prevent SAMS [46, 47]. Myopathy is a general term encompassing all forms of muscle disease, including toxic disorders as well as acquired and heritable metabolic disorders. The term does not necessarily connote symptoms or any degree of CK elevation. Muscle biopsy also suggests some myopathic statin-induced abnormalities that may be present in the context of normal CK levels [43].

Myositis with muscle inflammation is associated with other symptoms (e.g., tenderness to palpation), CK elevation, and leukocyte infiltration into muscle tissue. Myonecrosis is always associated with muscle injury and elevation of serum CK [29]. The most serious, and fortunately very rare, form of myonecrosis is rhabdomyolysis (1.6 per 100,000 patient-years), in which muscle breakdown is responsible for a massive release of CK and myoglobin, with resulting myoglobinuria and acute renal failure [29]. However, rhabdomyolysis currently occurs principally in cases of genetic predisposition as well as drug-drug interactions [48]. According to the EAS consensus paper on SAMS, it is important to remember the cut-off point value of 4 , above which muscle symptoms seem to be more attributable to statin therapy [24].

\subsubsection{Biomarkers of Statin Intolerance}

New biomarkers for statin-induced myopathy are emerging. Unfortunately, most cannot be commonly used because of complexities in methodology and costs, and their sensitivity and specificity still need to be defined [11]. The most widely used serum marker is the serum CK level [49], but its exclusive use as a diagnostic marker is inadequate and non-specific because high serum levels are not always associated with myopathy [50]. CK levels can be elevated by exercise in a dose-independent manner [29] and by drug interactions, genetic variants, CoQ10 deficiency, and vitamin D deficiency [51].

Routine liver function analyses are no longer recommended in the management of statin therapy because the diagnostic yield is low and not cost effective [11]. Statinassociated liver abnormalities (aminotransferase levels) are rare, mild, dose-related, and not related to reduction in LDL-C. Thus, drug- and dose-specific effects are more important determinants of liver and muscle toxicity than magnitude of LDL-C lowering [52, 53]. They are also usually temporary, and it is possible to return to baseline levels after 2-4 weeks [52, 53]. Persistent elevation of ALT more than three times the upper limit of normal (ULN) were observed in $\leq 1 \%$ of patients treated with statins. These are dose related, with rates of $<0.5 \%$ for moderate-dose rosuvastatin and at all doses, and slightly higher rates (about 1\%) with atorvastatin or simvastatin $80 \mathrm{mg}$ [52]. ALT elevations often improve even when statin therapy is continued. The incidence of liver failure is the same among statin-treated patients as in the general population not treated with statins [54]. Finally, it is worth remembering that the use of statins prevents about $33 \%$ of major CVD events when compared with placebo, and statins may cause serious liver disease in $1 / 1,000,000$ ( $\mathrm{NNH}$ is 1 million). Between 10 and $30 \%$ of patients do not receive statins because of fear of hepatotoxicity [14, 23].

Other early markers also might predict and diagnose statin intolerance [11]. One such biomarker being considered, at least in in vitro experiments, is lactate dehydrogenase, but its clinical utility in cases of statin-induced myopathy has not been validated [56]. A study that treated rats with drugs that are highly toxic to myocytes (carbamate acetylcholinesterase inhibitor; isoproterenol, a synthetic catecholamine), but not with statins, identified fatty acid binding protein 3 (FABP3) and myosin light chain 1 (MLC1) as biomarkers of skeletal muscle toxicity based on the specific tissue distribution of these proteins $[55,56]$. Burch et al. [57] evaluated skeletal muscle troponin I (sTnI), myosin light chain 3 (MYL3 [S3]), CK isoform M (CKM), and FABP3 compared with $\mathrm{CK}$ in the monitoring of drug-induced skeletal muscle injury. sTnI, MYL3, $\mathrm{CKM}$, and FABP3 all outperformed CK and/or added value for the diagnosis of drug-induced novel skeletal muscle injury (i.e., myocyte degeneration/necrosis) [57]. In addition, when used in conjunction with CK, sTnI, MYL3, CKM, and FABP3 individually and collectively improved diagnostic sensitivity and specificity, as well as diagnostic certainty, for novel skeletal muscle injury and responded in a sensitive manner to low levels of novel skeletal muscle injury degeneration/necrosis in rats. CKM showed the strongest correlation $(r=0.47, p<0.0001)$, followed by FABP3 $(r=0.52, \quad p<0.0001), \quad$ MYL3 $\quad(r=0.48$, $p<0.0001), \quad$ sTnI $\quad(r=0.47, \quad p<0.0001), \quad$ aspartate transaminase (AST; $r=0.46, \quad p<0.0001$ ), and CK $(r=0.32, p<0.0001)$ [57]. These findings support the suggestion that STnI, MYL3, CKM, and FABP3 are suitable for voluntary use, in conjunction with $\mathrm{CK}$, in 
regulatory safety studies in rats to monitor drug-induced skeletal muscle injury and for the potential translational use of these exploratory biomarkers in early clinical trials to ensure patient safety [57]. Dobkin [58] suggested the functional evaluation of hip-flexor and abductor performance (because it occurred independently of CK levels). $\mathrm{Wu}$ et al. [59] proposed the evaluation of the kinetics of recovery exercise phosphocreatine by means of phosphorus magnetic resonance spectroscopy $\left({ }^{31} \mathrm{P}-\mathrm{MRS}\right)$. In this study, patients were treated for 4 weeks with statin therapy and were shown to have a prolonged metabolic recovery time in the calf despite no change in serum CK levels [59]. Unfortunately, several drawbacks are associated with these muscle-specific markers: rapid clearance, dependence of renal dysfunction, heterogeneous response depending on the type of myotoxicants in general, and the difficulty and high costs of measurements [11, 60].

Laaksonen et al. [61] proposed lipidomic evaluation of plasma muscle gene profiles, which helped to identify several sensitive biomarkers of metabolic alterations induced in skeletal muscle by high-dose statin regimens (increased expression of arachidonic acid 5-lipoxygenase activating protein, phospholipase $\mathrm{C}$, numerous species of phosphatidylethanolamine, selective pools of long-chain triglycerides, and phosphocholine ether). However, such complex genomic and combined lipidomic analyses are very difficult to perform and, above all, to interpret routinely in clinical practice. Two microRNAs (miRNAs; $133 \mathrm{a} / \mathrm{b}$ and 499-5p) were evaluated as potential biomarkers of tissue damage because of their long half-lives in serum. The serum levels of $\mathrm{miR}-133 \mathrm{a} / \mathrm{b}$ were reported as sensitive and specific markers of cardiac and skeletal muscle toxicity [62]; miR-499-5p might serve as a biomarker for statinenhanced muscle injury during exercise because it was increased in the plasma of runners after a marathon and increased when muscle contraction was combined with exposure to statins [63]. Further studies are still necessary to confirm the specificity and sensitivity of innovative biomarkers in statin-treated patients.

\subsubsection{Statin Intolerance Management}

Probably the most important issue in the management of patients with statin intolerance/SAMS is the need to continue statin therapy. It is especially critical for patients with high and very high CV risk, as therapy discontinuation for 4-6 weeks might cause atheroma plaque instability [64] and increases the risk of $\mathrm{CV}$ events [17]. A further aspect to consider is inflammation. Sposito et al. [65] assessed the existence of a rebound inflammatory effect after statin withdrawal in the acute phase of MI. At baseline, statin users presented with a lower C-reactive protein (CRP) than patients not receiving a statin before the MI. By the fifth day post-MI, median CRP was significantly higher in the group from whom statins had been withdrawn.

Complete statin intolerance, which requires statin discontinuation, affects $<5 \%$ of patients with statin intolerance symptoms [23, 25]. Numerous approaches to maintaining statin persistence have been published [24, 25, 29, 34]. Therefore, we would especially like to focus on combination therapy for patients not able to tolerate suitable statin doses. Briefly, we can always consider step-by-step reduction of the dose (dechallenge) and intermittent dosages (alternate-day therapy). We know this does not significantly influence the magnitude of LDL-C reduction for rosuvastatin and atorvastatin [66]. The lipophilicity and hydrophilicity of statins seems to be important, and changing from a hydrophilic to a lipophilic statin may be of some benefit in the SAMS setting [23, 24]. We have also observed that both statin groups had the same effects concerning efficacy and safety in patients with ACS [67]. Hydrophilic statins (rosuvastatin and pravastatin) seem to cause fewer statin intolerance symptoms, and this is especially important for elderly patients [23] (Table 2).

\subsection{Alternative Drug Treatment}

The use of lipid-lowering therapy in clinical practice has become progressively more challenging because exaggerated patient concerns over side effects and potential toxicity can lead to poor adherence to statin therapy or discontinuation [15, 22] despite the highly established benefits of LDL-C reduction [68, 69]. The use of ezetimibe monotherapy is still limited (due to US FDA recommendations in the USA as well as restricted reimbursement in Europe, leading to use in $<5-10 \%$ of the patients who require it according to guideline recommendations) [13], and use of the monoclonal antibodies directed against proprotein convertase subtilisin kexin type 9 (PCSK9) tends to be severely restricted by managed care formularies. Statin monotherapy or statin combination therapy with other currently available drugs do not all have the same capacity to induce appropriate reductions in LDL-C in patients at high $\mathrm{CV}$ risk [70]. Therefore, there is a clinical need for new therapies, alone or in combination with current drugs (Table 2), to lower LDL-C.

Bempedoic acid (ETC-1002) has a unique mechanism of action (adenosine triphosphate-citrate lyase inhibition) $[71,72]$. The efficacy of combination therapy with statins and bempedoic acid has been evaluated in a randomized controlled trial (NCT02072161) [73]. A total of 134 patients who had been treated with one of a series of statin regimens (atorvastatin 10 or $20 \mathrm{mg}$; simvastatin 5 , 10, or $20 \mathrm{mg}$; rosuvastatin 5 or $10 \mathrm{mg}$; or pravastatin 10 , 20, or $40 \mathrm{mg}$ ) for at least 3 months before the trial began were randomized to bempedoic acid 120 or $180 \mathrm{mg}$ or placebo 
Table 2 Therapeutic possibilities for the treatment of statin-intolerant patients and their influence on low-density lipoprotein cholesterol levels

\begin{tabular}{|c|c|c|c|c|c|}
\hline Agent & Subjects & Dose & Duration & LDL-C levels & References \\
\hline \multirow[t]{3}{*}{ BA with low-dose statins } & \multirow{3}{*}{$\begin{array}{l}134 \\
\text { hypercholesterolemic } \\
\text { pts }\end{array}$} & $120 \mathrm{mg} /$ day & \multirow[t]{3}{*}{12 weeks } & $\begin{array}{c}-17.3 \pm 4.0 \% \\
(p<0.01)\end{array}$ & \multirow[t]{3}{*}[73]{} \\
\hline & & $180 \mathrm{mg} /$ day & & $\begin{array}{c}-24.3 \pm 4.2 \% \\
(p<0.001)\end{array}$ & \\
\hline & & PL & & $-4.2 \pm 4.2 \%$ & \\
\hline BA & $\begin{array}{l}56 \\
\text { hypercholesterolemic } \\
\text { pts }\end{array}$ & $240 \mathrm{mg} /$ day vs. PL & $\begin{array}{l}8 \text { weeks } \\
\text { (increase } \\
\text { by } 60 \mathrm{mg} \\
\text { q2w) }\end{array}$ & $-28.7 \%(p<0.001)$ & {$[74]$} \\
\hline \multirow[t]{5}{*}{ BA with or without EZE } & \multirow{5}{*}{$\begin{array}{l}177 \\
\text { hypercholesterolemic } \\
\text { pts }\end{array}$} & $120 \mathrm{mg} /$ day & \multirow[t]{5}{*}{12 weeks } & $\begin{array}{l}-27.5 \pm 1.3 \mathrm{mg} / \mathrm{dl} \\
(p=0.0008)\end{array}$ & \multirow[t]{5}{*}[75]{} \\
\hline & & $180 \mathrm{mg} / \mathrm{day}$ & & $\begin{array}{c}-30.1 \pm 1.3 \mathrm{mg} / \mathrm{dl} \\
(p<0.0001)\end{array}$ & \\
\hline & & EZE $10 \mathrm{mg} /$ day & & $\begin{array}{l}-21.2 \pm 1.3 \mathrm{mg} / \mathrm{dl} \\
(p<0.0001)\end{array}$ & \\
\hline & & $120 \mathrm{mg}+\mathrm{EZE} 10 \mathrm{mg} / \mathrm{day}$ & & $\begin{array}{c}-43.1 \pm 2.6 \mathrm{mg} / \mathrm{dl} \\
(p<0.0001)\end{array}$ & \\
\hline & & $180 \mathrm{mg}+$ EZE $10 \mathrm{mg} /$ day & & $\begin{array}{l}-47.7 \pm 2.8 \mathrm{mg} / \mathrm{dl} \\
(p<0.0001)\end{array}$ & \\
\hline BA & $\begin{array}{l}\text { 12,600 statin-intolerant } \\
\text { pts expected }\end{array}$ & $180 \mathrm{mg} /$ day & 6 years & Ongoing & {$[76]$} \\
\hline \multirow[t]{3}{*}{ ATO } & \multirow{3}{*}{$\begin{array}{l}60 \\
\text { hypercholesterolemic } \\
\text { pts }\end{array}$} & $10 \mathrm{mg} /$ day & \multirow[t]{3}{*}{6 weeks } & $\begin{array}{l}100 \pm 25 \mathrm{mg} / \mathrm{dl} \\
(p=0.3)\end{array}$ & \multirow[t]{3}{*}{ [129] } \\
\hline & & $20 \mathrm{mg} /$ alternate day & & $68 \pm 28 \mathrm{mg} / \mathrm{dl}(p<1.0)$ & \\
\hline & & $20 \mathrm{mg} /$ day & & $96 \pm 41 \mathrm{mg} / \mathrm{dl}(p<1.0)$ & \\
\hline \multirow[t]{2}{*}{ ROS } & \multirow{2}{*}{$\begin{array}{l}45 \\
\text { hypercholesterolemic } \\
\text { pts }\end{array}$} & $20 \mathrm{mg} /$ alternate day & \multirow[t]{2}{*}{6 weeks } & $-40.9 \%(p<0.0001)$ & \multirow[t]{2}{*}[130]{} \\
\hline & & $10 \mathrm{mg} /$ day & & $-78.5 \%(p<0.0001)$ & \\
\hline \multirow[t]{2}{*}{ ATO } & \multirow{2}{*}{$\begin{array}{l}61 \\
\text { hypercholesterolemic } \\
\text { pts }\end{array}$} & $20 \mathrm{mg} /$ alternate day & \multirow[t]{2}{*}{3 months } & $\begin{array}{l}-95 \pm 31 \mathrm{mg} / \mathrm{dl} \\
(p<0.05)\end{array}$ & \multirow[t]{2}{*}{ [131] } \\
\hline & & $20 \mathrm{mg} /$ day & & $\begin{array}{l}-94 \pm 28 \mathrm{mg} / \mathrm{dl} \\
(p<0.05)\end{array}$ & \\
\hline \multirow[t]{2}{*}{ ROS } & \multirow[t]{2}{*}{37 dyslipidemic pts } & $10 \mathrm{mg} /$ alternate day & \multirow[t]{2}{*}{6 weeks } & $\begin{array}{c}-57 \pm 1.2 \mathrm{mg} / \mathrm{dl} \\
(p<0.01)\end{array}$ & \multirow[t]{2}{*}{ [132] } \\
\hline & & $10 \mathrm{mg} /$ day & & $\begin{array}{l}-60 \pm 1.0 \mathrm{mg} / \mathrm{dl} \\
(p<0.01)\end{array}$ & \\
\hline \multirow[t]{2}{*}{ PRA } & \multirow[t]{2}{*}{104 dyslipidemic pts } & Half-dose alternate days vs. daily & \multirow[t]{2}{*}{4 months } & $\begin{aligned} 113 & \pm 21 \mathrm{mg} / \mathrm{dl} \\
(p & <0.04)\end{aligned}$ & \multirow[t]{2}{*}{ [133] } \\
\hline & & & & $\begin{aligned} 104 & \pm 24 \mathrm{mg} / \mathrm{dl} \\
(p & <0.04)\end{aligned}$ & \\
\hline \multirow[t]{3}{*}{ ATO } & \multirow{3}{*}{$\begin{array}{l}54 \\
\text { hypercholesterolemic } \\
\text { pts }\end{array}$} & $10 \mathrm{mg} /$ day & \multirow[t]{3}{*}{6 weeks } & No statistically & \multirow[t]{3}{*}{ [134] } \\
\hline & & $10 \mathrm{mg} /$ alternate day & & significant differences & \\
\hline & & $20 \mathrm{mg} /$ alternate day & & $\begin{array}{l}\text { groups regarding total } \\
\text { or a percentage }\end{array}$ & \\
\hline ATO & 40 & $20 \mathrm{mg} /$ alternate day & 12 weeks & No statistically & {$[135]$} \\
\hline & $\begin{array}{l}\text { hypercholesterolemic } \\
\text { pts }\end{array}$ & $20 \mathrm{mg} /$ day & & $\begin{array}{l}\text { significant differences } \\
\text { between the two } \\
\text { groups }\end{array}$ & \\
\hline ATO & 60 pts with CAD & $10 \mathrm{mg} /$ alternate day & 6 weeks & $\begin{aligned} 105 & \pm 26 \mathrm{mg} / \mathrm{dl} \\
(p & <0.008)\end{aligned}$ & [136] \\
\hline & & $10 \mathrm{mg} /$ day & & $\begin{array}{c}88 \pm 21 \mathrm{mg} / \mathrm{dl} \\
(p<0.008)\end{array}$ & \\
\hline
\end{tabular}


Table 2 continued

\begin{tabular}{|c|c|c|c|c|c|}
\hline Agent & Subjects & Dose & Duration & LDL-C levels & References \\
\hline \multirow[t]{2}{*}{ FLU } & \multirow{2}{*}{$\begin{array}{l}23 \\
\text { hypercholesterolemic } \\
\text { pts }\end{array}$} & $40 \mathrm{mg} /$ alternate day & \multirow[t]{2}{*}{6 weeks } & $\begin{aligned} 144 & \pm 21 \mathrm{mg} / \mathrm{dl} \\
(p & <0.05)\end{aligned}$ & \multirow[t]{2}{*}{ [137] } \\
\hline & & $20 \mathrm{mg} /$ day & & $\begin{aligned} 138 & \pm 19 \mathrm{mg} / \mathrm{dl} \\
(p<0.05) & \end{aligned}$ & \\
\hline \multirow[t]{2}{*}{ ROS } & \multirow[t]{2}{*}{$\begin{array}{l}80 \text { pts with primary } \\
\text { hypercholesterolemia }\end{array}$} & $10 \mathrm{mg} /$ alternate day & \multirow[t]{2}{*}{8 weeks } & $\begin{array}{l}105.07 \pm 26.30 \mathrm{mg} / \mathrm{dl} \\
\quad(p<0.001)\end{array}$ & \multirow[t]{2}{*}{ [138] } \\
\hline & & $10 \mathrm{mg} /$ day & & $\begin{array}{l}94.10 \pm 40.16 \mathrm{mg} / \mathrm{dl} \\
\quad(p<0.001)\end{array}$ & \\
\hline \multirow[t]{2}{*}{ ATO } & \multirow[t]{2}{*}{100 dyslipidemic pts } & $10 \mathrm{mg} /$ alternate day & \multirow[t]{2}{*}{3 months } & $\begin{array}{l}73.6 \pm 14.71 \mathrm{mg} / \mathrm{dl} \\
(p<0.0001)\end{array}$ & \multirow[t]{2}{*}{ [139] } \\
\hline & & $10 \mathrm{mg} /$ day & & $\begin{array}{l}93.79 \pm 17.48 \mathrm{mg} / \mathrm{dl} \\
\quad(p<0.0001)\end{array}$ & \\
\hline ATO & $\begin{array}{l}141 \text { pts with } \\
\text { dyslipidemia or CAD }\end{array}$ & Alternate day vs. daily & 12 weeks & $\begin{array}{l}\text { Alternate-day dosing of } \\
\text { ATO was inferior to } \\
\text { daily dosing in } \\
\text { maintaining the } \\
\text { NCEP-ATP III goal }\end{array}$ & {$[140]$} \\
\hline EZE & $\begin{array}{l}432 \text { pts with primary } \\
\text { hypercholesterolemia }\end{array}$ & $\begin{array}{l}5 \mathrm{mg} / \text { day } \\
10 \mathrm{mg} / \text { day }\end{array}$ & 12 weeks & $\begin{array}{l}-15.7 \%(p<0.01) \\
-18.5 \%(p<0.01)\end{array}$ & {$[141]$} \\
\hline $\mathrm{EZE}+$ statins & $\begin{array}{l}769 \text { pts with primary } \\
\text { hypercholesterolemia }\end{array}$ & $\begin{array}{l}\text { Statin + EZE } 10 \mathrm{mg} / \text { day } \\
\text { Statin + PL }\end{array}$ & 8 weeks & $\begin{array}{l}-25.1 \%(p<0.001) \\
-3.7 \%(p<0.001)\end{array}$ & [142] \\
\hline $\mathrm{EZE}+\mathrm{SIM}$ & 720 pts with FH & $\mathrm{SIM}+\mathrm{EZE} 10 \mathrm{mg} /$ day & 24 months & $\begin{array}{l}141.3 \pm 52.6 \mathrm{mg} / \mathrm{dl} \\
\quad(p<0.01)\end{array}$ & {$[143]$} \\
\hline $\mathrm{EZE}+\mathrm{SIM}$ & $\begin{array}{l}1128 \text { pts with } \\
\text { hypercholesterolemia } \\
\text { and metabolic } \\
\text { syndrome }\end{array}$ & $\begin{array}{l}\text { EZE/SIM 10/20 mg/day } \\
\text { EZE/SIM 10/40 mg/day }\end{array}$ & 6 weeks & $\begin{array}{l}-49.6 \%(p<0.001) \\
-53.9 \%(p<0.001)\end{array}$ & [144] \\
\hline $\mathrm{EZE}+\mathrm{ROS}$ & $\begin{array}{l}239 \text { pts with high risk } \\
\text { of CHD }\end{array}$ & $\begin{array}{l}\text { EZE/ROS 10/40 mg/day } \\
\text { ROS } 40 \mathrm{mg}\end{array}$ & 6 weeks & $\begin{array}{l}-70 \%(p<0.001) \\
-56 \%(p<0.001)\end{array}$ & [145] \\
\hline $\begin{array}{l}\text { PCSK9 inhibitor EVO } \\
\text { with moderate- and } \\
\text { high- intensity statins }\end{array}$ & $\begin{array}{l}1117 \text { primary } \\
\text { hypercholesterolemia } \\
\text { and mixed } \\
\text { dyslipidemia pts }\end{array}$ & $\begin{array}{l}140 \text { mg vs. PL } \\
420 \text { mg vs. PL }\end{array}$ & $\begin{array}{l}10 \text { weeks } \\
12 \text { weeks }\end{array}$ & $\begin{array}{l}66-75 \%(p<0.001) \\
63-65 \%(p<0.001)\end{array}$ & {$[83]$} \\
\hline $\begin{array}{l}\text { PCSK9 inhibitor EVO } \\
\text { with statin or EZE }\end{array}$ & 1359 dyslipidemic pts & $\begin{array}{l}70 \mathrm{mg} \mathrm{q} 2 \mathrm{w}+\text { statin or EZE } \\
105 \mathrm{mg} \mathrm{q} 2 \mathrm{w}+\text { statin or EZE } \\
140 \mathrm{mg} \mathrm{q} 2 \mathrm{w}+\text { statin or EZE } \\
280 \mathrm{mg} \mathrm{q} 4 \mathrm{w}+\text { statin or EZE } \\
350 \mathrm{mg} \mathrm{q} 4 \mathrm{w}+\text { statin or EZE } \\
420 \mathrm{mg} \mathrm{q} 4 \mathrm{w} \text { or EZE }\end{array}$ & 12 weeks & $\begin{array}{l}-40.20 \%(p<0.001) \\
-52.86 \%(p<0.001) \\
-59.26 \%(p<0.001) \\
-42.55 \%(p<0.001) \\
-47.00 \%(p<0.001) \\
-52.66 \%(p<0.001)\end{array}$ & {$[86]$} \\
\hline $\begin{array}{l}\text { PCSK9 inhibitor EVO } \\
\text { with statin }\end{array}$ & $\begin{array}{l}511 \text { pts with } \\
\text { uncontrolled LDL-C } \\
\text { and history of } \\
\text { intolerance to two or } \\
\text { more statins }\end{array}$ & $420 \mathrm{mg} / \mathrm{month}$ & 24 weeks & $\begin{array}{c}-102.9 \mathrm{mg} / \mathrm{dl} \\
(p<0.001)\end{array}$ & {$[88]$} \\
\hline \multirow[t]{2}{*}{$\begin{array}{l}\text { PCSK9 inhibitor ALI } \\
\text { with EZE }\end{array}$} & \multirow{2}{*}{$\begin{array}{l}361 \text { pts at moderate to } \\
\text { high CV risk with } \\
\text { statin intolerance }\end{array}$} & ALI $75 \mathrm{mg} \mathrm{q} 2 \mathrm{w}$ & \multirow[t]{2}{*}{24 weeks } & $\begin{array}{c}-102.9 \mathrm{mg} / \mathrm{dl} \\
(p<0.001)\end{array}$ & \multirow[t]{2}{*}{ [96] } \\
\hline & & EZE $10 \mathrm{mg}$ & & $\begin{array}{c}-31.2 \mathrm{mg} / \mathrm{dl} \\
(p<0.001)\end{array}$ & \\
\hline Inclisiran with statin & $\begin{array}{l}501 \text { pts at high CVD } \\
\text { risk with elevated } \\
\text { LDL-C }\end{array}$ & $\begin{array}{l}\text { Single dose of } 200-500 \mathrm{mg} / \text { day } \\
\text { or double dose of } \\
100-300 \mathrm{mg} / \text { day }\end{array}$ & 180 days & $\begin{array}{l}27.9-41.9 \% \text { after a } \\
\text { single dose } \\
35.5-52.6 \% \text { after two } \\
\text { doses (for both } \\
p<0.001 \text { ) }\end{array}$ & [98] \\
\hline
\end{tabular}


Table 2 continued

\begin{tabular}{|c|c|c|c|c|c|}
\hline Agent & Subjects & Dose & Duration & LDL-C levels & $\overline{\text { References }}$ \\
\hline Red yeast rice DS & $\begin{array}{l}83 \text { pts in dietary } \\
\text { treatment }\end{array}$ & $2.4 \mathrm{~g} /$ day red yeast rice & 12 weeks & $\begin{array}{l}\text { From } 4.47 \pm 0.70 \text { to } \\
\quad 3.49 \pm 0.70(p<0.05)\end{array}$ & [99] \\
\hline $\begin{array}{l}\text { Plant extracts (red yeast } \\
\text { rice, sugar cane-derived } \\
\text { policosanols, and } \\
\text { artichoke leaf extracts) }\end{array}$ & $\begin{array}{l}39 \text { pts with moderate } \\
\text { hypercholesterolemia }\end{array}$ & $\begin{array}{l}\text { Red yeast rice } 166.67 \mathrm{mg}(0.4 \% \\
\text { monacolin } \mathrm{K}) \text {, sugar cane } \\
\text { extract } 3.70 \mathrm{mg}(90 \% \\
\text { policosanols-octacosanol } 60 \%) \text {, } \\
\text { artichoke leaf dry extract } \\
200 \mathrm{mg} \text { (5-6\% chlorogenic } \\
\text { acid) daily }\end{array}$ & 16 weeks & $-14.1 \%(p<0.001)$ & [102] \\
\hline $\begin{array}{l}\text { Natural nutraceuticals } \\
\text { (red yeast, policosanol, } \\
\text { and berberine) }\end{array}$ & 933 dyslipidemic pts & 1 tablet/day associated with diet & 16 weeks & $-23.5 \%(p<0.001)$ & [103] \\
\hline $\begin{array}{l}\text { Nutraceutical } \\
\text { combination (red yeast } \\
\text { rice extract, berberine, } \\
\text { policosanol, } \\
\text { astaxanthin, CoQ10, } \\
\text { folic acid) }\end{array}$ & $\begin{array}{l}30 \text { pts with moderate } \\
\mathrm{CV} \text { risk }\end{array}$ & $\begin{array}{l}\text { Berberine } 500 \mathrm{mg} \text {, policosanols } \\
10 \mathrm{mg} \text {, folic acid } 0.2 \mathrm{mg}, \\
\text { CoQ10 } 2.0 \mathrm{mg} \text {, astaxanthin } \\
0.5 \mathrm{mg} \text { daily }\end{array}$ & 8 weeks & $-21.1 \%(p<0.001)$ & {$[104]$} \\
\hline $\begin{array}{l}\text { Acid ethyl ester } \\
\text { (AMR101) }\end{array}$ & 702 statin-treated pts & 4 or $2 \mathrm{~g} /$ day & 12 weeks & $-6.2 \%(p=0.0067)$ & [112] \\
\hline $\begin{array}{l}\text { Chokeberry flavonoid } \\
\text { extract }\end{array}$ & 44 pts after MI & $\begin{array}{l}85 \mathrm{mg} \text { tid of chokeberry flavonoid } \\
\text { extract (Aronia melanocarpa } \mathrm{E} \text {.) }\end{array}$ & 6 weeks & $\begin{array}{l}\text { Ox-LDL levels }-29 \% \\
\quad(p<0.000)\end{array}$ & {$[114]$} \\
\hline Spirulina & $312 \mathrm{pts}$ & $1-10 \mathrm{~g} /$ day & $2-12$ months & $\begin{array}{c}-41.32 \mathrm{mg} / \mathrm{dl} \\
(p<0.001)\end{array}$ & [116] \\
\hline \multirow[t]{2}{*}{ BER vs. EZE } & \multirow[t]{2}{*}{$\begin{array}{l}228 \text { pts with primary } \\
\text { hypercholesterolemia }\end{array}$} & $\begin{array}{l}\text { Berberine } 500 \mathrm{mg} \text {, policosanol } \\
10 \mathrm{mg} \text {, red yeast rice } 200 \mathrm{mg}\end{array}$ & \multirow[t]{2}{*}{6 months } & $-31.7 \%(p<0.001)$ & \multirow[t]{2}{*}{ [146] } \\
\hline & & EZE $10 \mathrm{mg} /$ day & & $-25.4 \%(p<0.001)$ & \\
\hline
\end{tabular}

$A E s$ adverse events, $A L I$ alirocumab, $A T O$ atorvastatin, $B A$ bempedoic acid, $B E R$ berberine, $C A D$ coronary artery disease, $C H D$ coronary heart disease, $C o Q 10$ coenzyme Q10, $C V$ cardiovascular, $C V D$ cardiovascular disease, $D S$ dietary supplement, $E V O$ evolocumab, $E Z E$ ezetimibe, $F H$ familial hypercholesterolemia, FLU fluvastatin, $L D L-C$ low-density lipoprotein cholesterol, $M I$ myocardial infarction, NCEP-ATP III National Cholesterol Education Program Adult Treatment Panel III, ND not defined, $O x$ - $L D L$ oxidized low-density lipoprotein, $P C S K 9$ proprotein convertase subtilisin/kexin type $9, P L$ placebo, $P R A$ pravastatin, $p t s$ patients, $q x w$ every $x$ weeks, ROS rosuvastatin, SIM simvastatin, tid three times daily

[73]. LDL-C was reduced significantly with bempedoic acid 120 or $180 \mathrm{mg}$ daily, respectively, compared with placebo: $-17.3 \pm 4.0 \% \quad(p<0.01)$ and $-24.3 \pm 4.2 \%$ $(p<0.001)$ [73]. Thompson et al. [74] conducted a multicenter, double-blind, 8-week trial in a group of patients intolerant to at least one statin and reported that ETC-1002 was effective at reducing LDL-C (by almost 29\%) and was well tolerated in patients with SAMS. A recent phase IIb trial in which patients with and without statin intolerance received daily treatment with ETC-1002 120 or $180 \mathrm{mg}$ alone or with ezetimibe confirmed these results. These treatments reduced LDL-C more than did ezetimibe alone and had a similar tolerability profile [75]. It is worth mentioning that a new phase III trial (NCT02993406) investigating whether treatment with bempedoic acid versus placebo decreases the risk of $\mathrm{CV}$ events in 12,600 statin-intolerant patients has commenced [76] (Table 2).

PCSK9 monoclonal antibodies constitute a breakthrough for statin-intolerant patients or those in whom LDL-C is not adequately managed with statins [77-79]. Evolocumab and alirocumab have recently received marketing authorization in the EU and the USA [79]. The approved indications for evolocumab are (1) adults with primary hypercholesterolemia (heterozygous familial hypercholesterolemia $[\mathrm{HeFH}]$ and non-familial), unable to achieve LDL-C goals with the maximum tolerated dose of a statin or alone or in combination with other lipid-lowering therapies in patients who are intolerant to statins, or for whom a statin is contraindicated; (2) adults and adolescents aged $\geq 12$ years with homozygous familial hypercholesterolaemia $(\mathrm{HoFH})$ in combination with other lipid-lowering therapies [80]. Alirocumab is approved for adults with primary hypercholesterolemia ( $\mathrm{HeFH}$ and non-familial) or mixed dyslipidemia, in patients unable to achieve their LDL-C goals with maximum tolerated dose of a statin or, alone or in combination with other lipid-lowering therapies, in patients who are intolerant to statins or for whom a statin is contraindicated [81]. 
Evolocumab and alirocumab have been studied in numerous phase II and phase III clinical trials involving high-risk patients, including those with statin intolerance and those with familial hypercholesterolemia (FH) [82-88]. Evolocumab reduces LDL-C by approximately $60-65 \%$, influences all other lipid profile parameters, and has favorable effects on lipoprotein(a) [89-92]. Evolocumab is also very well tolerated as monotherapy, added to statins, or added to statins plus ezetimibe [82], without major adverse effects such as myalgia, CK elevations, NOD [93], or neurocognitive disorders [94]. In a pooled analysis of four phase III studies, the effectiveness and safety of evolocumab was comparable in patients with or without type 2 DM (T2DM) and did not differ between T2DM subgroups [82]. Toth et al. [87] reported a comprehensive safety assessment of evolocumab in 6026 patients in 12 phase II and III parent trials with a median exposure of 2.8 months, and in 4465 of those patients who continued with a median follow-up of 11.1 months in two open-label extension (OLE) trials, demonstrating a favorable benefit-risk profile for evolocumab. Overall adverse event (AE) rates were similar between evolocumab and control groups in the parent trials (51.1 vs. $49.6 \%$ ) and in year 1 of the OLE trials (70.0 vs. 66.0\%), as were those for serious AEs (SAEs). Elevations of serum transaminases, bilirubin, and $\mathrm{CK}$ were infrequent and similar between groups [87]. Muscle-related AEs were similar between evolocumab and control groups. Neurocognitive AEs were infrequent and balanced during the double-blind parent studies (five events [0.1\%] in the evolocumab groups vs. six events [0.3\%] in the control groups). No neutralizing anti-evolocumab antibodies were detected [87]. The GAUSS-3 (Goal Achievement after using an anti-PCSK9 antibody Intolerant statins subject-3) trial was a statin intolerance study that included 511 adult patients with a history of intolerance to two or more statins [88]. Patients were treated with non-statin therapies (evolocumab vs. ezetimibe). After 2 years, LDL-C levels were significantly more reduced (by $36.1 \%$ ) in the evolocumab group than in the ezetimibe group $(p<0.001)$. Muscle symptoms were reported in $28.8 \%$ of ezetimibe-treated patients and $20.7 \%$ of evolocumab-treated patients $(p=0.17)$ [88]. The recently published FOURIER (Further Cardiovascular Outcomes Research with PCSK9 Inhibition in Subjects with Elevated Risk) trial provided strong evidence on $\mathrm{CV}$ endpoints and additional long-term safety (mean 26 months) in 27,564 patients with established CVD (MI, ischemic stroke, or symptomatic peripheral artery disease). Patients were randomized to receive either subcutaneous evolocumab $140 \mathrm{mg}$ every 2 weeks, subcutaneous evolocumab $420 \mathrm{mg}$ every month, or matching placebo injections [95]. All patients were receiving background statin therapy (almost 70\% receiving high-intensity statin therapy). The addition of evolocumab to statin therapy (with or without ezetimibe) significantly reduced the primary endpoint (composite of CV death, MI, stroke, hospitalization for unstable angina, or coronary revascularization) and key secondary endpoints (composite of $\mathrm{CV}$ death, MI, or stroke) of the trial by $15 \%$ (hazard ratio [HR] $0.85 ; 95 \%$ confidence interval [CI] 0.79-0.92; $p<0.001)$ and $20 \%$ (HR $0.80 ; 95 \%$ CI $0.73-0.88$; $p<0.001)$, respectively [95].

The available evidence for alirocumab suggests that this treatment is also (similarly) effective in reducing LDL-C and is well tolerated. The results of the ODYSSEY ALTERNATIVE trial in patients with statin intolerance demonstrated good tolerability and efficacy [96]. The ODYSSEY phase III program includes more than 23,000 patients and 14 studies with alirocumab alone or in combination with other lipid-lowering agents, and as monotherapy in patients with primary $\mathrm{HeFH}$, non-FH, or statin intolerance [97]. The ODYSSEY OUTCOMES study is not yet completed (it will likely be presented at the American College of Cardiology meeting in March 2018) and is assessing the CV benefit of alirocumab in 18,600 patients (at higher risk than in the FOURIER trial), over approximately 5 years of follow-up (the mean follow-up will be at least 3 years). A subgroup analysis of 2341 patients with and without T2DM in ODYSSEY LONGTERM showed that alirocumab effects were also consistent, regardless of the clinical history of patients with T2DM at baseline [97] (Table 2).

Another approach to PCSK9 inhibition is in development. The ORION-1 (Trial to Evaluate the Effect of ALNPCSSC Treatment on LDL-C) trial found that inclisiran, a chemically synthesized small interfering RNA designed to target PCSK9 messenger RNA, lowered PCSK9 and LDL$\mathrm{C}$ levels among patients at high $\mathrm{CV}$ risk who had elevated LDL-C levels [98]. In this trial, over the course of 180 days, 501 patients received a single dose of inclisiran 200,300 , or $500 \mathrm{mg}$ or two doses (at days 1 and 90) of inclisiran 100, 200, or $300 \mathrm{mg}$ [98]. At day 180, inclisiran significantly reduced ( $p<0.001$ vs. placebo) LDL-C levels from 27.9 to $41.9 \%$ after a single dose and 35.5 to $52.6 \%$ after two doses. Two doses of inclisiran $300 \mathrm{mg}$ produced the greatest reduction in LDL cholesterol levels at day 180 (48\% of patients had LDL-C $<50 \mathrm{mg} / \mathrm{dl}[<1.3 \mathrm{mmol} / \mathrm{l}]$ ) [98]. At day 240, PCSK9 and LDL-C levels remained significantly lower than at baseline with all inclisiran regimens. Inclisiran may emerge as an important therapeutic option for statin-intolerant patients, as lipid-lowering occurs with few serious AEs or symptoms of immune system activation [98] (Table 2). An advantage of this drug is that it can be can be administered every 6 months.

This class of new drugs will be used in the long term, generally for the rest of the treated patients' lives. Despite 
claims that millions of patients with dyslipidemia could benefit from these PCSK9 inhibitors, these treatments will actually meet the health needs of a small population of patients (at very high $\mathrm{CV}$ risk who benefit the most) because of the high costs in all countries in which they are marketed.

\subsection{Alternative Nutraceutical Therapy}

It is known that lipid-lowering therapy might not be enough to completely attenuate the risk of CVD, residual risk still exists, and that alternative therapy with nutraceuticals may help improve therapy adherence and reduce the risk of patients with statin intolerance [37]. Natural products can be used in combination with a nonstatin (as well as with small doses of synthetic or natural statins) in subjects with statin intolerance.

Monacolins such as policosanols and bergamot inhibit HMG-CoA reductase, and red yeast rice extract (Monascus purpureus) contains a variety of monacolins [99]. A 2005 study in 111 Caucasian individuals demonstrated that a brand dietary supplement comprising $M$. purpureus titrated extract and octacosanols, which contain a low dose of niacin, resulted in LDL-C lowering by $20 \%(p<0.001)$ and a reduction of triglyceride plasma level by $16 \%(p<0.01)$ in patients with moderate hypercholesterolemia with no clinically relevant changes in muscle and liver toxicity markers [100]. LDL-C lowering was similar to that obtained with pravastatin [100]. Red yeast rice used in combination with plant sterols mimicked the effect of statins and ezetimibe by significantly lowering LDL-C by $33 \%$ and total cholesterol by $19 \%$ in only 6 weeks of nutraceutical therapy [101]. Red yeast rice extract contains nine varieties of bioactive constituents (monacolins) with the same formulation as lovastatin. Furthermore, co-administration of leaf extracts and red yeast rice significantly reduced LDL-C $(21.4 \% ; p<0.001)$ and total cholesterol $(14.1 \% ; p<0.001)$ after 16 weeks [102]. The combination of berberine with red yeast rice significantly improved different lipid parameters (i.e., lowered total cholesterol, LDL-C, and triglyceride levels $[p<0.001$ for all] and increased HDL-C concentration $[p<0.001])$ after 16 weeks of treatment [103]. Comparable results were observed in another clinical trial [104]. This study showed results similar to those with pravastatin in subjects with moderate dyslipidemia and metabolic syndrome: the same combination induced an increase of $4.8 \%$ in HDL-C and a lowering of $21.1 \%$ in total cholesterol and $21.1 \%$ in LDL-C [104]. In the setting of statin intolerance, Armolipid Plus ${ }^{\circledR}$, a formulation that contains natural substances (red yeast rice, policosanol, and berberine combined with folic acid, astaxanthin, and coQ10) with putative complementary lipid-lowering properties, offers an effective alternative devoid of the safety risks associated with synthetic pharmacological therapy because it has a combination of low doses of its active ingredients-low enough not to be associated with untoward effects but high enough to exert therapeutic effects in combination with other complementary substances [105]. Armolipid Plus ${ }^{\circledR}$ can reduce total cholesterol (11-21\%) and LDL-C (15-31\%) levels, which is equivalent to changes associated with low-dose statins. In patients with mild to moderate hyperlipidemia intolerant to statins who do not achieve LDL-C targets with ezetimibe, Armolipid Plus ${ }^{\circledR}$ can promote a further $10 \%$ reduction in total cholesterol and LDL-C. Moreover, Armolipid Plus ${ }^{\circledR}$ offers additional benefits in terms of improvements in vascular stiffness, which is an independent predictor of CV events [105].

The mechanism of action of policosanol, a mix of eight long-chain aliphatic alcohols derived from the fermentation of sugar cane, rice, wheatgerm, or sunflower seeds is not yet clear [106]. Data on the lipid-lowering effects of policosanols are contradictory. The down-regulation of cell HMG-CoA reductase by this formulation has been proposed [107]. Its lipid-lowering activity might be comparable to that of statins, and it may be even more effective at increasing HDL-C and lowering side effects [108]; however, the data on their actual effectiveness are still contradictory [106, 109-111]. Further research is needed to determine with certainty whether policosanols have beneficial lipid-lowering effects and whether they might have beneficial effects for patients who are intolerant to statins.

The efficacy of icosapent ethyl (IPE; Vascepa ${ }^{\circledR}$ [formerly AMR101]; Amarin Pharma Inc., Bedminster, NJ, USA) in improving lipid parameters was demonstrated in a 12-week randomized, placebo-controlled trial (ANCHOR) that enrolled statin-treated patients at high $\mathrm{CV}$ risk with well-controlled LDL-C levels and persistently high triglyceride levels ( $\geq 200$ and $<500 \mathrm{mg} / \mathrm{dl}$ ) [112]. Compared with placebo, IPE 4 and $2 \mathrm{~g}$ daily reduced median triglyceride levels from baseline by $21.5 \%(p<0.0001)$ and $10.1 \% \quad(p=0.0005)$, respectively, without increasing LDL-C levels. The 4-g daily dose decreased LDL-C levels by $6.2 \%(p=0.007)$ and significantly reduced other lipid parameters compared with a light liquid paraffin placebo, including apolipoprotein B $(9.3 \% ; p<0.0001)$, very lowdensity lipoprotein cholesterol (VLDL-C) (24.4\%; $p<0.0001)$, lipoprotein-associated phospholipase A2 (19.0\%; $p<0.0001)$, and high-sensitivity CRP (hsCRP) (22.0\%; $p=0.0005)$ [112]. One study of IPE in statinintolerant patients suggested it might be potentially effective in this group of patients [113].

In a double-blind study, Naruszewicz et al. [114] used chokeberry extract in 44 patients (11 women and 33 men, mean age 66 years) who survived an MI and received statin therapy for at least 6 months $(80 \%$ dose of simvastatin 
$40 \mathrm{mg}$ daily) [114]. Subjects were randomized to receive either chokeberry flavonoid extract (Aronia melanocarpa E.) $85 \mathrm{mg}$ three times daily or placebo for 6 weeks. The study extract comprised the following constituents: anthocyanins (about 25\%), polymeric procyanidins (about 50\%), and phenolic acids (about 9\%) [114]. Compared with placebo, flavonoids significantly reduced serum 8-isoprostans $(p<0.000)$ and oxidized LDL levels $(p<0.000)$ (by 38 and $29 \%$, respectively), as well as hsCRP $(p<0.007)$ and monocyte chemoattractant protein-1 (MCP-1) $(p<0.001)$ levels (by 23 and 29\%, respectively). In addition, significant increases in adiponectin $(p<0.03)$ levels and reductions in systolic and diastolic blood pressure, by a mean average of 11 and $7.2 \mathrm{mmHg}$, respectively, were found [114]. The abovementioned results mean this extract is potentially beneficial for statin-intolerant patients, but further studies in these subjects are necessary to definitively confirm its effectiveness and safety profile.

Spirulina is a filamentous, water blue-green microalga (Cyanobacterium) [115]. The hypolipemic properties of spirulina have not been conclusively studied. One metaanalysis [116] of seven randomized controlled trials showed a significant effect from supplementation with spirulina, with reduced plasma concentrations of total cholesterol $\quad(-46.76 \mathrm{mg} / \mathrm{dl} ; \quad p<0.001)$, LDL-C $\quad(-$ $41.32 \mathrm{mg} / \mathrm{dl} ; \quad p<0.001)$, triglycerides $(-44.23 \mathrm{mg} / \mathrm{dl}$; $p<0.001)$, and elevated levels of HDL-C $(6.06 \mathrm{mg} / \mathrm{dl}$; $p=0.001)$. The impact of spirulina on plasma concentrations of total cholesterol and triglycerides was independent of administered dose (dose range: $1-10 \mathrm{~g} /$ day). Spirulina contains high levels of antioxidants (e.g., beta-carotene), phycocyanin, microelements (K, Na, Ca, Mg, Fe, Zn), vitamins (tocopherols), eight necessary amino acids, polyunsaturated fatty acids (PUFAs) — especially $\gamma$-linolenic acid-and phenolic compounds [117]; however, the active components responsible for the hypolipidemic effects of spirulina are not fully understood. This metaanalysis was the first to evaluate the effects of spirulina supplementation on serum lipid parameters based on the results from randomized controlled trials, but further welldesigned trials are required to clarify the clinical value of spirulina supplementation as an add-on to conventional and novel lipid-lowering therapies in patients with dyslipidemia.

Curcumin, a natural dietary polyphenol responsible for the yellow color of the Indian spice turmeric (Curcuma longa L.), has analgesic, antioxidant [118], and anti-inflammatory properties relevant to the treatment of SAMS as it prevents and reduces muscular fatigue, blocks the inflammatory pathway of the nuclear factor, attenuates muscular atrophy, and improves regeneration of muscle fibers after injuries [119]. Since curcumin also has lipidmodifying properties, it may serve as an additive to therapy in patients with SAMS, enabling effective reduction of LDL-C and possibly a lower statin dose [120]. Curcumin may modulate the production of HDL and biomarkers of HDL functionality by increasing apolipoprotein AI (apoAI) and lecithin cholesterol acyl transferase (LCAT) and decreasing cholesteryl ester transfer protein (CETP), paraoxonase-1 (PON1), myeloperoxidase (MPO), and lipoprotein-associated phospholipase A2 (Lp-PLA2) [121]. Curcumin is safe to consume, even at dosages of up to 8-12 g daily [122]; however, so far, its low bioavailability and efficacy profile in vivo has limited its clinical application [123]. Further clinical trials with curcumin formulations with improved bioavailability are necessary to examine its effects on lipid metabolism and SAMS treatment.

Several nutraceuticals exert lipid-lowering and atheroprotective properties [124-126]. Berberine, curcumin, polydatin, n-3 PUFA-enriched fish oil, docosahexaenoic acid (DHA)-enriched canola oil, marine n-3 PUFAs, and quercetin-3-O-b-D-glucoside have been identified as able to lower PCSK9 levels, an important regulator of lipid metabolism and an efficient target for plasma LDL-C reduction [127]. In particular, the use of some of these agents is supported by data from human trials in patients with at least one condition related to the metabolic syndrome, $\mathrm{HeFH}$, or dyslipidemia. Administration of a pill containing berberine $500 \mathrm{mg}$ for 6 months reduced LDL-C by $10.5 \%(p<0.0001)$ in patients with $\mathrm{HeFH}$, an effect the authors suggested was associated with an indirect berberine-mediated inhibitory effect on PCSK9 [127]. Xuezhikang is a cholestin extract that contains a mixture of lovastatin (dominant compound), plant sterols, and isoflavones. Administration of xuezhikang $1200 \mathrm{mg}$ daily for 8 weeks increased plasma PCSK9 levels by $34 \%$ $(p=0.006)$ and decreased LDL-C and total cholesterol by 28 and 22\% ( $p=0.001, p=0.002)$, respectively [127]. Enrichment of canola oil with DHA was shown to lower circulating PCSK9 and triacylglycerol levels by $6 \%$. Furthermore, circulating PCSK9 levels were found to be significantly and positively associated with LDL-C, triacylglycerol, and apolipoprotein B (apoB) levels, whereas no association was found between PCSK9 and HDL-C levels [127]. Consumption of marine n-3 PUFAs $2200 \mathrm{mg}$ daily for 12 weeks decreased circulating PCSK9 levels by 11.4 and $9.8 \%$ in premenopausal and postmenopausal women, respectively. In contrast, plasma LDL-C levels showed no significant changes [127].

Therefore, some nutraceuticals such as berberine and curcumin are suggested as useful adjuncts to statin therapy because of their inhibition of PCSK9 independent of sterolresponsive element-binding protein. Nevertheless, evidence from well-designed randomized controlled trials is required to support the added value of such a combination 
in reducing $\mathrm{CV}$ events compared with statin monotherapy [127] (Table 2).

\section{Conclusions}

Statins are generally safe and very efficacious agents for reducing the burden of atherogenic lipoproteins in serum and the risk for acute CV events, including MI, stroke, death, and need for revascularization. The most common statinrelated side effect associated with therapy non-adherence and discontinuation is myalgia. Statin discontinuation out of exaggerated toxicity-related concerns is a significant problem worldwide and appears to be growing. Negative press reporting about statin therapy is highly correlated with statin discontinuation and significantly increased risk for $\mathrm{CV}$ morbidity and mortality [128]. A step-by-step approach, including careful examination of all other possible factors that may increase the risk of statin intolerance, might help patients continue statin therapy when experiencing statinassociated side effects. Complete statin intolerance is relatively rare $(<5 \%)$, and for these patients as well as for those who can only tolerate low-to-moderate dose statin therapy and require incremental LDL-C reduction, consideration should be given to the use of ion-exchange resin (if available), ezetimibe, and the PCSK9 inhibitors. Ongoing investigation into whether bempedoic acid and inclisiran with or without statin therapy are well tolerated in the longer term is needed. Interest in the efficacy of nutraceuticals for dyslipidemia management in patients with statin intolerance is increasing. Although the LDL-C reduction potential of these compounds is promising, they have not yet been tested in clinical trials powered for clinical endpoints, and they might be considered, especially when other means with which to achieve the LDL-C goal of the therapy are lacking. However, further studies in patients intolerant to statins are necessary to confirm their effectiveness and safety.

\section{Compliance with Ethical Standards}

Funding This review was written independently. The authors did not receive financial or professional help with the preparation of the manuscript.

Conflict of interest Maciej Banach has no conflicts of interest that might be relevant to the contents of this manuscript. Peter P. Toth has previously received consulting fees and/or honoraria from AbbVie, Amarin, Amgen, Gemphire, Kowa, Merck, Regeneron, and Sanofi and payment for lectures from Amarin, Amgen, Kowa, Merck, Regeneron, and Sanofi. Rosaria Vincenza Giglio, Giuseppa Castellino, Angelo Maria Patti, and Dragana Nikolic have participated in clinical trials sponsored by AstraZeneca and Novo Nordisk. Manfredi Rizzo has given lectures, received honoraria and research support, and participated in conferences, advisory boards, and clinical trials sponsored by AstraZeneca, Boehringer Ingelheim, Kowa, Eli Lilly, Merck Sharp \& Dohme, Novo Nordisk, Novartis, and Roche.
Open Access This article is distributed under the terms of the Creative Commons Attribution-NonCommercial 4.0 International License (http://creativecommons.org/licenses/by-nc/4.0/), which permits any noncommercial use, distribution, and reproduction in any medium, provided you give appropriate credit to the original author(s) and the source, provide a link to the Creative Commons license, and indicate if changes were made.

\section{References}

1. Katsiki N, Mikhailidis DP, Banach M. Effects of statin treatment on endothelial function, oxidative stress and inflammation in patients with arterial hypertension and normal cholesterol levels. J Hypertens. 2011;29(12):2493-4.

2. Raju SB, Varghese K, Madhu K. Management of statin intolerance. Indian J Endocrinol Metab. 2013;17:977-82.

3. Bosomworth NJ. Approach to identifying and managing atherogenic dyslipidemia: a metabolic consequence of obesity and diabetes. Can Fam Physician. 2013;59:1169-80.

4. Banach M, Mikhailidis DP, Kjeldsen SE, et al. Time for new indications for statins? Med Sci Monit. 2009;15:MS1-5.

5. Ford ES, Ajani UA, Croft JB, et al. Explaining the decrease in U.S. deaths from coronary disease, 1980-2000. N Engl J Med. 2007;356:2388-98.

6. Cholesterol Treatment Trialists' (CTT) Collaboration, Baigent C, Blackwell L, et al. Efficacy and safety of more intensive lowering of LDL cholesterol: a meta-analysis of data from 170,000 participants in 26 randomised trials. Lancet. 2010;376:1670-81.

7. Stone NJ, Robinson JG, Lichtenstein AH, et al. 2013 ACC/AHA guideline on the treatment of blood cholesterol to reduce atherosclerotic cardiovascular risk in adults: a report of the American College of Cardiology/American Heart Association Task Force on Practice Guidelines. J Am Coll Cardiol. 2014;63:2889-934.

8. Hobbs FD, Banach M, Mikhailidis DP, et al. Is statin-modified reduction in lipids the most important preventive therapy for cardiovascular disease? A pro/con debate. BMC Med. 2016;14:4.

9. Colantonio LD, Bittner V, Reynolds K, et al. Association of serum lipids and coronary heart disease in contemporary observational studies. Circulation. 2016;133:256-64.

10. Baigent C, Keech A, Kearney PM, et al. Efficacy and safety of cholesterol-lowering treatment: prospective meta-analysis of data from 90,056 participants in 14 randomised trials of statins. Lancet. 2005;366:1267-78.

11. Muntean DM, Thompson PD, Catapano AL, et al. Statin-associated myopathy and the quest for biomarkers: can we effectively predict statin-associated muscle symptoms? Drug Discov Today. 2017;22:85-96.

12. Gluba-Brzozka A, Franczyk B, Toth PP, et al. Molecular mechanisms of statin intolerance. Arch Med Sci. 2016;12:645-58.

13. Patel J, Martin SS, Banach M. Expert opinion: the therapeutic challenges faced by statin intolerance. Expert Opin Pharmacother. 2016;17:1497-507.

14. Banach M, Rizzo M, Toth PP, et al. Statin intolerance-an attempt at a unified definition. Position paper from an International Lipid Expert Panel. Arch Med Sci. 2015;11:1-23.

15. Banach M, Serban MC. Discussion around statin discontinuation in older adults and patients with wasting diseases. J Cachexia Sarcopenia Muscle. 2016;7:396-9. 
16. Jackevicius CA, Mamdani M, Tu JV. Adherence with statin therapy in elderly patients with and without acute coronary syndromes. JAMA. 2002;288:462-7.

17. Serban MC, Colantonio LD, Manthripragada AD, et al. Statin intolerance and risk of coronary heart events and all-cause mortality following myocardial infarction. J Am Coll Cardiol. 2017;69:1386-95

18. Banach M, Stulc T, Dent R, et al. Statin non-adherence and residual cardiovascular risk: there is need for substantial improvement. Int J Cardiol. 2016;225:184-96.

19. Saeed B, Wright E, Evans W, et al. PS1-45: prevalence of statin intolerance in a high-risk cohort and management strategies in contemporary cardiology. Clin Med Res. 2013;11:136.

20. Algharably EA, Filler I, Rosenfeld S, et al. Statin intolerance-a question of definition. Expert Opin Drug Saf. 2017;16:55-63.

21. Mancini GB, Baker S, Bergeron J, et al. Diagnosis, prevention, and management of statin adverse effects and intolerance: proceedings of a Canadian Working Group Consensus Conference. Can J Cardiol. 2011;27:635-62.

22. Jacobson TA, Ito MK, Maki KC, et al. National Lipid Association recommendations for patient-centered management of dyslipidemia: part 1 -executive summary. J Clin Lipidol. 2014;8:473-88.

23. Banach M, Rizzo M, Toth PP, et al. Statin intolerance-an attempt at a unified definition. Position paper from an International Lipid Expert Panel. Expert Opin Drug Saf. 2015; 14:935-55.

24. Stroes ES, Thompson PD, Corsini A, et al. Statin-associated muscle symptoms: impact on statin therapy-European Atherosclerosis Society Consensus Panel Statement on Assessment, Aetiology and Management. Eur Heart J. 2015;36:1012-22.

25. Mancini GB, Baker S, Bergeron J, et al. Diagnosis, prevention, and management of statin adverse effects and intolerance: Canadian Consensus Working Group Update (2016). Can J Cardiol. 2016;32:S35-65.

26. Mancini GB, Tashakkor AY, Baker S, et al. Diagnosis, prevention, and management of statin adverse effects and intolerance: Canadian Working Group Consensus update. Can J Cardiol. 2013;29:1553-68.

27. Stulc T, Ceška R, Gotto AM Jr. Statin intolerance: the clinician's perspective. Curr Atheroscler Rep. 2015;17:69.

28. Parker BA, Capizzi JA, Grimaldi AS, et al. Effect of statins on skeletal muscle function. Circulation. 2013;127:96-103.

29. Thompson PD, Clarkson PM, Rosenson RS, National Lipid Association Statin Safety Task Force Muscle Safety Expert Panel. An assessment of statin safety by muscle experts. Am J Cardiol. 2006;97:69C-76C.

30. Waters DD, Ho JE, DeMicco DA, et al. Predictors of new-onset diabetes in patients treated with atorvastatin: results from 3 large randomized clinical trials. J Am Coll Cardiol. 2011;57:1535-45.

31. Preiss D, Seshasai S, Welsh P, et al. Risk of incident diabetes with intensive-dose compared with moderate-dose statin therapy: a meta-analysis. JAMA. 2011;305:2556-64.

32. Barylski M, Nikolic D, Banach M, et al. Statins and new-onset diabetes. Curr Pharm Des. 2014;20:3657-64.

33. Banach M, Malodobra-Mazur M, Gluba A, et al. Statin therapy and new-onset diabetes: molecular mechanisms and clinical relevance. Curr Pharm Des. 2013;19:4904-12.

34. Authors Task Force, Members Catapano AL, Graham I, et al. ESC/EAS Guidelines for the Management of Dyslipidaemias: The Task Force for the Management of Dyslipidaemias of the European Society of Cardiology (ESC) and European Atherosclerosis Society (EAS) Developed with the special contribution of the European Association for Cardiovascular
Prevention \& Rehabilitation (EACPR). Atherosclerosis. 2016;2016(253):281-344.

35. Banach M, Mikhailidis DP. Statin therapy and new-onset diabetes: an attempt at recommendations. Expert Rev Endocrinol Metab. 2013;8:213-6.

36. Ridker PM, Pradhan A, MacFadyen JG, et al. Cardiovascular benefits and diabetes risks of statin therapy in primary prevention: an analysis from the JUPITER trial. Lancet. 2012;380:565-71.

37. Banach M, Jankowski P, Jóźwiak J, et al. PoLA/CFPiP/PCS guidelines for the management of dyslipidaemias for family physicians 2016. Arch Med Sci. 2017;13:1-45.

38. Bays H. Statin safety: an overview and assessment of the data2005. Am J Cardiol. 2006;97:6C-26C.

39. Joy TR, Hegele RA. Narrative review: statin-related myopathy. Ann Intern Med. 2009;150:858-68.

40. Grundy SM. Can statins cause chronic low-grade myopathy? Ann Intern Med. 2002;137:617-8.

41. Bruckert E, Hayem G, Dejager S, et al. Mild to moderate muscular symptoms with high-dosage statin therapy in hyperlipidemic patients- the PRIMO study. Cardiovasc Drugs Ther. 2005; 19:403-14.

42. Cohen JD, Brinton EA, Ito MK, et al. Understanding Statin Use in America and Gaps in Patient Education (USAGE): an internet-based survey of 10,138 current and former statin users. J Clin Lipidol. 2012;6:208-15.

43. Phillips PS, Haas RH, Bannykh S, et al. Statin-associated myopathy with normal creatine kinase levels. Ann Intern Med. 2002;137:581-5.

44. Rosenson RS, Baker SK, Jacobson TA, Kopecky SL, Parker BA. An assessment by the Statin Muscle Safety Task Force: 2014 update. J Clin Lipidol. 2014;8:S58-71.

45. Rosenson RS, Baker S, Banach M, et al. Optimizing cholesterol treatment in patients with muscle complaints. J Am Coll Cardiol. 2017;70:1290-301.

46. Michalska-Kasiczak M, Sahebkar A, Mikhailidis DP, et al. Analysis of vitamin D levels in patients with and without statinassociated myalgia - a systematic review and meta-analysis of 7 studies with 2420 patients. Int J Cardiol. 2015;178:111-6.

47. Banach M, Serban C, Sahebkar A, et al. Lipid and Blood Pressure Meta-Analysis Collaboration Group. Effects of coenzyme Q10 on statin-induced myopathy: a meta-analysis of randomized controlled trials. Mayo Clin Proc. 2015;90:24-34.

48. Vrablik M, Zlatohlavek L, Stulc T, et al. Statin-associated myopathy: from genetic predisposition to clinical management. Physiol Res. 2014;63(Suppl 3):S327-34.

49. Di Stasi SL, MacLeod TD, Winters JD, et al. Effects of statins on skeletal muscle: a perspective for physical therapists. Phys Ther. 2010;90:1530-42.

50. Kearns AK, Bilbie CL, Clarkson PM, et al. The creatine kinase response to eccentric exercise with atorvastatin $10 \mathrm{mg}$ or $80 \mathrm{mg}$. Atherosclerosis. 2008;200:121-5.

51. Deichmann RE, Lavie CJ, Asher T, et al. The interaction between statins and exercise: mechanisms and strategies to counter the musculoskeletal side effects of this combination therapy. Ochsner J. 2015;15:429-37.

52. Davidson MH, Robinson JG. Safety of aggressive lipid management. J Am Coll Cardiol. 2007;49:1753-62.

53. Alsheikh-Ali AA, Maddukuri PV, Han H, Karas RH. Effect of the magnitude of lipid lowering on risk of elevated liver enzymes, rhabdomyolysis, and cancer: insights from large randomized statin trials. J Am Coll Cardiol. 2007;50:409-18.

54. Cohen DE, Anania FA, Chalasani N, National Lipid Association Statin Safety Task Force Liver Expert Panel. An assessment of statin safety by hepatologists. Am J Cardiol. 2006;97:C77-81. 
55. Vaklavas C, Chatzizisis YS, Ziakas A, et al. Molecular basis of statin-associated myopathy. Atherosclerosis. 2009;202:18-28.

56. Tonomura Y, Mori Y, Torii M, et al. Evaluation of the usefulness of biomarkers for cardiac and skeletal myotoxicity in rats. Toxicology. 2009;266:48-54.

57. Burch PM, Greg Hall D, Walker EG, et al. Evaluation of the relative performance of drug-induced skeletal muscle injury biomarkers in rats. Toxicol Sci. 2016;150:247-56.

58. Dobkin BH. Underappreciated statin-induced myopathic weakness causes disability. Neurorehabilit Neural Repair. 2005;19:259-63.

59. Wu JS, Buettner C, Smithline H, Ngo LH, et al. Evaluation of skeletal muscle during calf exercise by 31-phosphorus magnetic resonance spectroscopy in patients on statin medications. Muscle Nerve. 2011;43:76-81.

60. Tonomura Y, Matsushima S, Kashiwagi E, et al. Biomarker panel of cardiac and skeletal muscle troponins, fatty acid binding protein 3 and myosin light chain 3 for the accurate diagnosis of cardiotoxicity and musculoskeletal toxicity in rats. Toxicology. 2012;302:179-89.

61. Laaksonen R, Katajamaa M, Päivä $\mathrm{H}$, et al. A systems biology strategy reveals biological pathways and plasma biomarker candidates for potentially toxic statin-induced changes in muscle. PLoS One. 2006;1:e97.

62. Calvano J, Achanzar W, Murphy B, et al. Evaluation of microRNAs-208 and $133 \mathrm{a} / \mathrm{b}$ as differential biomarkers of acute cardiac and skeletal muscle toxicity in rats. Toxicol Appl Pharmacol. 2016;312:53-60.

63. Min PK, Park J, Isaacs S, et al. Influence of statins on distinct circulating microRNAs during prolonged aerobic exercise. J Appl Physiol. 2016;120:711-20.

64. Banach M, Serban C, Sahebkar A, et al. Impact of statin therapy on coronary plaque composition: a systematic review and metaanalysis of virtual histology intravascular ultrasound studies. BMC Med. 2015;13:229.

65. Sposito AC, Carvalho LS, Cintra RM, et al. Brasilia Heart Study Group. Rebound inflammatory response during the acute phase of myocardial infarction after simvastatin withdrawal. Atherosclerosis. 2009;207(1):191-4.

66. Awad K, Mikhailidis DP, Toth PP, et al. On behalf of LBPMC Group. Efficacy and safety of alternate-day versus daily dosing of statins: a systematic review and meta-analysis. Cardiovasc Drugs Ther. 2017;31:419-31.

67. Bytyçi I, Bajraktari G, Bhatt DL, Morgan CJ, Ahmed A, Aronow WS, Banach M. Hydrophilic vs lipophilic statins in coronary artery disease: a meta-analysis of randomized controlled trials. J Clin Lipidol. 2017;11(3):624-37.

68. Serban MC, Banach M, Mikhailidis DP. Clinical implications of the IMPROVE-IT trial in the light of current and future lipidlowering treatment options. Expert Opin Pharmacother. 2016;17:369-80.

69. Sampson UK, Fazio S, Linton MF. Residual cardiovascular risk despite optimal LDL cholesterol reduction with statins: the evidence, etiology, and therapeutic challenges. Curr Atheroscler Rep. 2012;14:1-10.

70. Katsiki N, Nikolic D, Montalto G, et al. The role of fibrate treatment in dyslipidemia: an overview. Curr Pharm Des. 2013;19:3124-31.

71. Nikolic D, Mikhailidis DP, Davidson MH, et al. ETC-1002: a future option for lipid disorders? Atherosclerosis. 2014;237:705-10.

72. Penson P, McGowan M, Banach M. Evaluating bempedoic acid for the treatment of hyperlipidaemia. Expert Opin Investig Drugs. 2017;26:251-9.

73. Ballantyne CM, McKenney JM, MacDougall DE, et al. Effect of ETC-1002 on serum low-density lipoprotein cholesterol in hypercholesterolemic patients receiving statin therapy. Am J Cardiol. 2016;117:1928-33.

74. Thompson PD, Rubino J, Janik MJ, et al. Use of ETC-1002 to treat hypercholesterolemia in patients with statin intolerance. J Clin Lipidol. 2015;9:295-304.

75. Thompson PD, MacDougall DE, Newton RS, et al. Treatment with ETC-1002 alone and in combination with ezetimibe lowers LDL cholesterol in hypercholesterolemic patients with or without statin intolerance. J Clin Lipidol. 2016;10:556-67.

76. https://clinicaltrials.gov/ct2/show/NCT02993406. Accessed 11 Nov 2017.

77. Stoekenbroek RM, Kastelein JJ, Huijgen R. PCSK9 inhibition: the way forward in the treatment of dyslipidemia. BMC Med. 2015; 13:258.

78. Zimmerman MP. How do PCSK9 inhibitors stack up to statins for low-density lipoprotein cholesterol control? Am Health Drug Benefits. 2015;8:436-42.

79. Dadu RT, Ballantyne CM. Lipid lowering with PCSK9 inhibitors. Nat Rev Cardiol. 2014;11:563-75.

80. http://www.medicines.org.uk/emc/medicine/30627. Accessed 11 Nov 2017.

81. http://www.medicines.org.uk/emc/medicine/30965. Accessed 11 Nov 2017.

82. Sattar N, Preiss D, Robinson JG, et al. Lipid-lowering efficacy of the PCSK9 inhibitor evolocumab (AMG 145) in patients with type 2 diabetes: a meta-analysis of individual patient data. Lancet Diabetes Endocrinol. 2016;4:403-10.

83. Robinson JG, Nedergaard BS, Rogers WJ, et al. Effect of evolocumab or ezetimibe added to moderate- or high-intensity statin therapy on LDL-C lowering in patients with hypercholesterolemia: the LAPLACE-2 randomized clinical trial. JAMA. 2014;311:1870-82.

84. Preiss D. Should we worry about raised triglycerides: the controversy continues. In: 51st EASD annual meeting, Stockholm, Sweden; 2015.

85. Sattar N, Preiss D, Blom D, et al. Evaluation of the one-year efficacy, safety and glycaemic effects of evolocumab (AMG 145 ) in 4,802 subjects with, at high risk for, or at low risk for, diabetes mellitus. In: 51st EASD annual meeting, Stockholm, Sweden; 2015.

86. Stein EA, Giugliano RP, Koren MJ, et al. PROFICIO Investigators. Efficacy and safety of evolocumab (AMG 145), a fully human monoclonal antibody to PCSK9, in hyperlipidaemic patients on various background lipid therapies: pooled analysis of 1359 patients in four phase 2 trials. Eur Heart J. 2014;35:2249-59.

87. Toth PP, Descamps O, Genest J, et al. Pooled safety analysis of evolocumab in over 6000 patients from double-blind and openlabel extension studies. Circulation. 2017;135:1819-31.

88. Nissen SE, Stroes E, Dent-Acosta RE, et al. GAUSS-3 Investigators. Efficacy and tolerability of evolocumab vs ezetimibe in patients with muscle-related statin intolerance: the GAUSS-3 randomized clinical trial. JAMA. 2016;315:1580-90.

89. Giugliano RP, Desai NR, Kohli P, et al. LAPLACE-TIMI 57 Investigators. Efficacy, safety, and tolerability of a monoclonal antibody to proprotein convertase subtilisin/kexin type 9 in combination with a statin in patients with hypercholesterolaemia (LAPLACE-TIMI 57). Lancet. 2012;380:2007-17.

90. Robinson JG, Rogers WJ, Nedergaard BS, et al. Rationale and design of LAPLACE-2: a phase 3, randomized, double-blind, placebo-and ezetimibe-controlled trial evaluating the efficacy and safety of evolocumab in subjects with hypercholesterolemia on background statin therapy. Clin Cardiol. 2014;37:195-203.

91. Dragan S, Serban MC, Banach M. Proprotein convertase subtilisin/kexin 9 inhibitors: an emerging lipid-lowering therapy? J Cardiovasc Pharmacol Ther. 2015;20:157-68. 
92. Kotani K, Banach M. Lipoprotein(a) and inhibitors of proprotein convertase subtilisin/kexin type 9. J Thorac Dis. 2017;9:E78-82.

93. Momtazi AA, Banach M, Pirro M, et al. PCSK9 and diabetes: is there a link? Drug Discov Today. 2017;22:883-95.

94. Banach M, Rizzo M, Nikolic D, et al. Intensive LDL-cholesterol lowering therapy and neurocognitive function. Pharmacol Ther. 2017;170:181-91.

95. Sabatine MS, Giugliano RP, Keech AC, Honarpour N, Wiviott SD, Murphy SA, Kuder JF, Wang H, Liu T, Wasserman SM, Sever PS, Pedersen TR, FOURIER Steering Committee and Investigators. Evolocumab and clinical outcomes in patients with cardiovascular disease. $\mathrm{N}$ Engl J Med. 2017;376(18):1713-22.

96. Moriarty PM, Thompson PD, Cannon CP, et al. ODYSSEY ALTERNATIVE Investigators. Efficacy and safety of alirocumab vs ezetimibe in statin-intolerant patients, with a statin rechallenge arm: the ODYSSEY ALTERNATIVE randomized trial. J Clin Lipidol. 2015;9:758-69.

97. Colhoun HM, Ginsberg HN, Leiter LA, et al. Efficacy and safety of alirocumab in individuals with diabetes: analyses from the ODYSSEY LONG TERM study. In: 51st EASD annual meeting, Stockholm, Sweden; 2015.

98. Ray KK, Landmasses U, Leiter LA, et al. Inclisiran in patients at high cardiovascular risk with elevated LDL cholesterol. N Engl J Med. 2017;376:1430-40.

99. Heber D, Yip I, Ashley JM, et al. Cholesterol-lowering effects of a proprietary Chinese red-yeast-rice dietary supplement. Am J Clin Nutr. 1999;69:231-6.

100. Cicero AF, Brancaleoni M, Lathi L, et al. Antihyperlipidemic effect of a Monascus purpureus brand dietary supplement on a large sample of subjects at low risk for cardiovascular disease: a pilot study. Complement Ther Med. 2005;13:273-8.

101. Feuerstein JS, Berker WS. Powdered red yeast rice and plant stanols and sterols to lower cholesterol. J Diet Suppl. 2012;9:110-5.

102. Ogier N, Amiot MJ, Georgé S, et al. LDL-cholesterol-lowering effect of a dietary supplement with plant extracts in subjects with moderate hypercholesterolemia. Eur J Nutr. 2013;52:547-57.

103. Trimarco B, Benvenuti C, Rozza F, et al. Clinical evidence of efficacy of red yeast rice and berberine in a large controlled study versus diet. Med J Nutr Metab. 2011;4:133-9.

104. Ruscica M, Gomaraschi M, Mombelli G, et al. Nutraceutical approach to moderate cardiometabolic risk: results of a randomized, double-blind and crossover study with Armolipid Plus. J Clin Lipidol. 2014;8:61-8.

105. Barrios V, Escobar C, Cicero AF, et al. A nutraceutical approach (Armolipid Plus) to reduce total and LDL cholesterol in individuals with mild to moderate dyslipidemia: review of the clinical evidence. Atheroscler Suppl. 2017;24:1-15.

106. Houston M. The role of nutraceutical supplements in the treatment of dyslipidemia. J Clin Hypertens (Greenwich). 2012;14:121-32.

107. Menéndez R, Amor AM, Rodeiro I, et al. Policosanol modulates HMG-CoA reductase activity in cultured fibroblasts. Arch Med Res. 2001;32:8-12.

108. Janikula M. Policosanol: a new treatment for cardiovascular disease? Altern Med Rev. 2002;7:203-17.

109. Berthold HK, Unverdorben S, Degenhardt R, et al. Effect of policosanol on lipid levels among patients with hypercholesterolemia or combined hyperlipidemia: a randomized controlled trial. JAMA. 2006;295:2262-9.

110. Cubeddu LX, Cubeddu RJ, Heimowitz T, et al. Comparative lipid-lowering effects of policosanol and atorvastatin: a randomized, parallel, double-blind, placebo-controlled trial. Am Heart J. 2006;152:982.
111. Dulin MF, Hatcher LF, Sasser HC, et al. Policosanol is ineffective in the treatment of hypercholesterolemia: a randomized controlled trial. Am J Clin Nutr. 2006;84:1543-8.

112. Ballantyne CM, Bays HE, Kastelein JJ, et al. Efficacy and safety of eicosapentaenoic acid ethyl ester (AMR101) therapy in statintreated patients with persistent high triglycerides (from the ANCHOR study). Am J Cardiol. 2012;110:984-92.

113. Reddy KJ, Chowdhury S. Improving lipids with prescription icosapent ethyl after previous use of fish oil dietary supplements. Future Cardiol. 2016;12:261-8.

114. Naruszewicz M, Laniewska I, Millo B, et al. Combination therapy of statin with flavonoids rich extract from chokeberry fruits enhanced reduction in cardiovascular risk markers in patients after myocardial infraction (MI). Atherosclerosis. 2007; 194:e179-84.

115. Thengodkar RR, Sivakami S. Degradation of Chlorpyrifos by an alkaline phosphatase from the cyanobacterium Spirulina platensis. Biodegradation. 2010;21:637-44.

116. Serban MC, Sahebkar A, Dragan S, et al. A systematic review and meta-analysis of the impact of Spirulina supplementation on plasma lipid concentrations. Clin Nutr. 2016;35:842-51.

117. Joventino IP, Alves HG, Neves LC, et al. The microalga Spirulina platensis presents anti-inflammatory action as well as hypoglycemic and hypolipidemic properties in diabetic rats. J Complement Integr Med. 2012;9:Article 17.

118. Panahi Y, Sahebkar A, Parvin S, Saadat A. A randomized controlled trial of anti-inflammatory effects of curcumin in patients with chronic syphur mustard-induced skin complications. Ann Clin Biochem. 2012;49:580-8.

119. Epstein J, Sanderson IR, MacDonald TT. Curcumin as a therapeutic agent: the evidence of in vitro, animal and human studies. Br J Nutr. 2010;103:1545-57.

120. Sahebkar A, Sabon N, Pirro M, et al. Curcumin: an effective adjunct in patients with statin-associated muscle symptoms? J Cachexia Sarcopenia Muscle. 2017;8:19-24.

121. Ganjali S, Blesso CN, Banach M, et al. Effects of curcumin on HDL functionality. Pharmacol Res. 2017;119:208-18.

122. Sahebkar A. Curcuminoids for the management of hypertriglyceridaemia. Nat Rev Cardiol. 2014;11:123.

123. Zhang P, Bai H, Liu G, et al. MicroRNA-33b, upregulated by EF24, a curcumin analog, suppresses the epithelial-to-mesenchymal transition (EMT) and migratory potential of melanoma cells by targeting HMGA2. Toxicol Lett. 2015;234:151-61.

124. Cicero AFG, Colletti A, Bajraktari G, et al. Lipid lowering nutraceuticals in clinical practice: position paper from an International Lipid Expert Panel. Arch Med Sci. 2017;13:965-1005.

125. Sahebkar A, Serban MC, Gluba-Brzózka A, et al. Lipid-modifying effects of nutraceuticals: an evidence-based approach. Nutrition. 2016;32:1179-92.

126. Pirro M, Vetrani C, Bianchi $C$, et al. Joint position statement on "Nutraceuticals for the treatment of hypercholesterolemia" of the Italian Society of Diabetology (SID) and of the Italian Society for the Study of Arteriosclerosis (SISA). Nutr Metab Cardiovasc Dis. 2017;27:2-17.

127. Momtazi AA, Banach M, Pirro M, et al. Regulation of PCSK9 by nutraceuticals. Pharmacol Res. 2017;120:157-69.

128. Nielsen SF, Nordestgaard BG. Negative statin-related news stories decrease statin persistence and increase myocardial infarction and cardiovascular mortality: a nationwide prospective cohort study. Eur Heart J. 2016;37:908-16.

129. Aghasadeghi K, Zare D. Efficacy of alternate day dosing of atorvastatin. Cent Eur J Med. 2008;3:163. 
130. Dulay D, LaHaye SA, Lahey KA, et al. Efficacy of alternate day versus daily dosing of rosuvastatin. Can $\mathrm{J}$ Cardiol. 2009;25:e28-31.

131. Keleş T, Akar Bayram N, Kayhan T, et al. The comparison of the effects of standard $20 \mathrm{mg}$ atorvastatin daily and $20 \mathrm{mg}$ atorvastatin every other day on serum LDL-cholesterol and high sensitive C-reactive protein levels. Anadolu Kardiyol Derg. 2008;8:407-12.

132. Li J-J, Yang P, Liu J, et al. Impact of $10 \mathrm{mg}$ rosuvastatin daily or alternate-day on lipid profile and inflammatory markers. Clin Chim Acta. 2012;413:139-42.

133. Graham MR, Lindsey CC, Kennedy JA. Maintenance of lowdensity lipoprotein goal with step-down pravastatin therapy. Pharmacotherapy. 2002;22:21-6.

134. Jafari M, Ebrahimi R, Ahmadi-Kashani M, et al. Efficacy of alternate-day dosing versus daily dosing of atorvastatin. J Cardiovasc Pharmacol Ther. 2003;8:123-6.

135. Pramanik S, Das AK, Chakrabarty M, et al. Efficacy of alternate-day versus everyday dosing of atorvastatin. Indian J Pharmacol. 2012;44:362-5.

136. Rifaie O, Zahran A, Nammas W. Alternate-day versus daily atorvastatin in coronary artery disease: a randomized study. Anatol J Cardiol. 2012;2:90-6.

137. Rindone JP, Hiller D, Arriola G. A comparison of fluvastatin 40 $\mathrm{mg}$ every other day versus $20 \mathrm{mg}$ every day in patients with hypercholesterolemia. Pharmacotherapy. 1998;18:836-9.

138. Wongwiwatthananukit S, Sansanayudh N, Dhummauppakorn R, et al. Efficacy and Safety of Rosuvastatin Every Other Day Compared with Once Daily in Patients with Hypercholesterolemia. Ann Pharmacother. 2006;40:1917-23.

139. Ghia CJ, Panda AS, Khobragade LR, et al. Alternate Day versus Once Daily Atorvastatin for Primary Prevention of (CHD) in
Naïve Patients of Dyslipidemia. J Clin Diagn Res. 2014;8:27-31.

140. Pattanaik S, Malhotra S, Sharma YP, et al. Comparison of Alternate-day Atorvastatin Treatment to Daily Treatment in Maintaining LDL-cholesterol Targets in Patients With Variable Coronary Risk Profile. J Cardiovasc Pharmacol. 2012;59:479-84.

141. Bays HE, Moore PB, Drehobl MA, et al. Effectiveness and tolerability of ezetimibe in patients with primary hypercholesterolemia: pooled analysis of two phase II studies. Clin Ther 2001;23:1209-30.

142. Gagne C, Bays HE, Weiss SR, et al. Efficacy and safety of ezetimibe added to ongoing statin therapy for treatment of patients with primary hypercholesterolemia. Am J Cardiol 2002;90:1084-91.

143. Kastelein JJ, Akdim F, Stroes ES, et al. Simvastatin with or without ezetimibe in familial hypercholesterolemia. N Engl $\mathbf{J}$ Med 2008;358:1431-43.

144. Robinson JG, Ballantyne CM, Grundy SM, et al. Lipid-altering efficacy and safety of ezetimibe/simvastatin versus atorvastatin in patients with hypercholesterolemia and the metabolic syndrome (from the VYMET study). Am J Cardiol 2009;103:1694-702.

145. Ballantyne CM, Weiss R, Moccetti T, et al. Efficacy and safety of rosuvastatin $40 \mathrm{mg}$ alone or in combination with ezetimibe in patients at high risk of cardiovascular disease (results from the EXPLORER study). Am J Cardiol 2007;99:673-80.

146. Pisciotta L, Bellocchio A, Bertolini S. Nutraceutical pill containing berberine versus ezetimibe on plasma lipid pattern in hypercholesterolemic subjects and its additive effect in patients with familial hypercholesterolemia on stable cholesterol-lowering treatment. Lipids Health Dis. 2012;11:123. 